\title{
Dopamine-Dependent QR2 Pathway Activation in CA1 Interneurons Enhances Novel Memory Formation
}

\author{
${ }^{\circledR}$ Nathaniel L. Gould, ${ }^{1}{ }^{\circledR}$ Vijendra Sharma, ${ }^{1}$ Mohammad Hleihil, ${ }^{1}{ }^{\circledR}$ Sailendrakumar Kolatt Chandran, ${ }^{1}$ \\ Orit David, ${ }^{1}$ Efrat Edry, ${ }^{1,2}$ and ${ }^{\circledR}$ Kobi Rosenblum ${ }^{1,2}$ \\ ${ }^{1}$ Sagol Department of Neuroscience, University of Haifa, Mount Carmel, Haifa, 3498838, Israel, and ${ }^{2}$ Center for Gene Manipulation in the Brain, \\ University of Haifa, Mount Carmel, Haifa, 3498838, Israel
}

The formation of memory for a novel experience is a critical cognitive capacity. The ability to form novel memories is sensitive to age-related pathologies and disease, to which prolonged metabolic stress is a major contributing factor. Presently, we describe a dopamine-dependent redox modulation pathway within the hippocampus of male mice that promotes memory consolidation. Namely, following novel information acquisition, quinone reductase 2 (QR2) is suppressed by miRNA-182 (miR-182) in the CA1 region of the hippocampus via dopamine D1 receptor (D1R) activation, a process largely facilitated by locus coeruleus activity. This pathway activation reduces ROS generated by QR2 enzymatic activity, a process that alters the intrinsic properties of CA1 interneurons $3 \mathrm{~h}$ following learning, in a form of oxidative eustress. Interestingly, novel experience decreases QR2 expression predominately in inhibitory interneurons. Additionally, we find that in aged animals this newly described QR2 pathway is chronically under activated, resulting in miR-182 underexpression and QR2 overexpression. This leads to accumulative oxidative stress, which can be seen in CA1 via increased levels of oxidized, inactivated potassium channel Kv2.1, which undergoes disulfide bridge oligomerization. This newly described interneuron-specific molecular pathway lies alongside the known mRNA translation-dependent processes necessary for long-term memory formation, entrained by dopamine in CA1. It is a process crucial for the distinguishing features of novel memory, and points to a promising new target for memory enhancement in aging and age-dependent diseases.

Key words: dopamine; hippocampus; memory consolidation; novelty; protein synthesis; ROS

Significance Statement

One way in which evolution dictates which sensory information will stabilize as an internal representation, relies on information novelty. Dopamine is a central neuromodulator involved in this process in the mammalian hippocampus. Here, we describe for the first time a dopamine D1 receptor-dependent quinone reductase 2 pathway in interneurons. This is a targeted redox event necessary to delineate a novel experience to a robust long-term internal representation. Activation of this pathway alone can explain the effect novelty has on "flashbulb" memories, and it can become dysfunctional with age and diseases, such as Alzheimer's disease.

Received May 19, 2020; revised Sep. 18, 2020; accepted Sep. 21, 2020.

Author contributions: N.L.G. and K.R. designed research; N.L.G., V.S., M.H., S.K.C., O.D., E.E., and K.R. performed research; N.L.G., V.S., and K.R. analyzed data; N.L.G. and K.R. wrote the first draft of the paper; N.L.G. and K.R. edited the paper; N.L.G. and K.R. wrote the paper.

This work was supported by the Legacy Heritage Biomedical Science Partnership Program of the Israel Science Foundation Grant 604/15 to K.R. N.L.G. is a recipient of the University of Haifa President Fellowship for Excellent PhD students. We thank laboratory members of the K.R. laboratory and specifically Dr. Shunit Gal-Ben-Ari and Gila Scherer for valued input during the writing of the present work; Dr. Shahaf Edut for assistance with DAT Cre mice; Dr. Barak Carni and Dr. Corina Dolinger for veterinary supervision of the animal facilities; Prof. Eran Hornstein for guidance with the miR experiments; and Fadi Sheban for assistance in carrying out experiments and calibrating protocols.

The authors declare no competing financial interests.

Correspondence should be addressed to Kobi Rosenblum at kobir@psy.haifa.ac.il.

https://doi.org/10.1523/JNEUROSCI.1243-20.2020

Copyright $\odot 2020$ the authors

\section{Introduction}

Acquiring new information about the surrounding environment is essential for an animal's continued survival and adaptation (Squire et al., 2015; Eichenbaum, 2017). Memorizing new locations, events, objects, and the consequences of these experiences is dependent on the CA1 subregion of the dorsal hippocampus (Zola-Morgan et al., 1986; Remondes and Schuman, 2004; Gaskin et al., 2009). Upon experiencing such novel contextual sensory input, dopamine is released in CA1 and its release is tightly correlated to the novelty of the stimulus (Moreno-Castilla et al., 2017). The major dopaminergic input to the hippocampus is the locus coeruleus (LC), which is itself activated by novelty and quickly silenced with familiarity (Vankov et al., 1995; Kempadoo et al., 2016). Upon novel contextual stimuli, the LC affects the hippocampal state via, among other things, activation of dopamine D1/5 type receptors (D1R) (Lemon and Manahan- 
Vaughan, 2012). This affects CA1 at two time scales. First, it acts quickly on neurons of the hippocampus by enhancing synaptic plasticity, afferent input, and modulation of neurotransmitter release ( $\mathrm{Li}$ et al., 2003). The second time scale is a lingering entrainment of molecular cascades within the cells, a process that leads to transcriptional and translational changes that are persistent and necessary to enable hippocampal long-term memory formation (Rosenberg et al., 2014). Although much has been described regarding these processes, gaps remain in our understanding of hippocampal memory formation. An example is the unusual effect of hippocampal state change following novelty, in which inconsequential and otherwise weakly remembered events that occur close in time to incidental novelty, that would usually be forgotten, are consolidated to long-term memory (Salvetti et al., 2014). These "flashbulb" memories are able to consolidate because of the overriding "novelty state" caused by the novel stimulus driven neuromodulation, and they are also found in cortical learning (Merhav and Rosenblum, 2008; Takeuchi et al., 2016). This phenomenon, not being fully understood, highlights some of the unknown aspects of novelty learning and memory formation. Therefore, there are open questions regarding how dopamine causes this state change, hours following learning, and by what molecular and cellular mechanisms it carries out this effect.

Recently, we identified quinone reductase 2 (QR2) as an important component in novel taste memory formation in the anterior insular cortex (aIC), acting in parallel to the well-known and previously described mechanisms downstream to neuromodulation (Rappaport et al., 2015; Gould et al., 2020). QR2 is a poorly understood enzyme, which unlike its closely related antioxidant enzyme NQO1, does not recognize $\mathrm{NADH}$ as cofactor and acts on deleterious substrates which can lead to the generation of ROS (Cassagnes et al., 2015). Importantly, the removal of QR2 from the aIC $3 \mathrm{~h}$ following novel taste learning lowers physiological ROS locally, thus modulating redox-sensitive components, such as Kv2.1 channels in a form of closely controlled oxidative eustress (Niki, 2016; Gould et al., 2020).

Presently, we found that this newly described QR2 pathway is involved in novel memory formation in the hippocampus. Namely, we found that QR2 removal occurs in CA1 during hippocampal-dependent novel memory formation, and that removal of QR2 improves contextual memory, while modulating redox there. We further found that in the hippocampus, D1R activation by dopaminergic input arising mainly from the LC leads to increased miR-182 expression which suppresses QR2 locally, leading to the enhanced memory observed with novelty. Additionally, we established that QR2 is primarily expressed in inhibitory neurons, where its expression is most strongly suppressed following a hippocampal-relevant novel experience. From a cellular perspective, this suppression directly reduces the excitability of inhibitory, but not excitatory neurons, thus lessening inhibition. Finally, we found that in aged mice the newly identified QR2 pathway is chronically suppressed, possibly contributing to cognitive decline and oxidative stress. Our findings provide a better understanding of how dopamine acts in the hippocampus to allow memory consolidation of novel information via activation of the QR2 pathway, pointing to $\mathrm{QR} 2$ as a promising therapeutic target for memory impairment conditions.

\section{Materials and Methods}

Subjects

Two- to 20-month-old, 20-35 g C57BL/6 (Envigo), Gad2-IRES-Cre and DAT-Cre mice (The Jackson Laboratory stocks 010802 and 006660 , respectively) male mice were used. Animals were housed in the
University of Haifa animal core facilities, within a temperature-controlled environment $\left(22^{\circ} \mathrm{C}-24^{\circ} \mathrm{C}\right)$, with a $12 \mathrm{~h} \mathrm{light/dark}$ cycle (light phase 07:00-19:00). All experiments were approved by the University of Haifa Animal Care and Use committee (license numbers 557/18, 536/17, $488 / 17,487 / 17,486 / 17,437 / 16)$. Animals were given at least $7 \mathrm{~d}$ of acclimatization, and were handled in accordance with University of Haifa practices and standards, which are in compliance with the National Institutes of Health guidelines for the ethical treatment of animals.

\section{Animal behavior}

Delay and trace fear conditioning (TFC). Animals were handled for a week, following a previous week, at least, of acclimatization to the animal facilities and were kept in groups of 2-5. Mice were brought into a red light illuminated conditioning room and were kept for $2 \mathrm{~min}$ in their cage. Mice were then placed within a Habitest Operant Cage, which was placed within a Habitest Isolation Cubicle (Coulbourn). Operant cages were equipped with 16 metal grid modular shock floors connected to Precision Animal Shockers (Coulbourn), and were illuminated with a 20 W light bulb. Video was acquired with a Sentec stc-tb33usb-at camera. For delay conditioning, the mice were allowed to explore the cage for $2 \mathrm{~min}$, and baseline freezing was measured before the presentation of the first tone. Then, following the $2 \mathrm{~min}$ period, mice experienced three trials consisting of a $20 \mathrm{~s} 4 \mathrm{kHz}, 80 \mathrm{~dB}$ tone (conditioned stimulus [CS]) immediately followed by $2 \mathrm{~s} 0.50 \mathrm{~mA}$ footshock (unconditioned stimulus [US]), with an intertrial interval of $1 \mathrm{~min}$. For TFC, mice were allowed to explore for $5 \mathrm{~min}$, and were then given 10 trials in which a $10 \mathrm{~s} 4 \mathrm{kHz}$, $80 \mathrm{~dB}$ tone was followed $20 \mathrm{~s}$ later by a $2 \mathrm{~s} 0.36 \mathrm{~mA}$ footshock, with a 3.5 min intertrial interval. Following the completion of the trials, the mice were kept for a further minute in the cages, before being removed. The following day, the mice were returned to the conditioning chambers with the contextual settings kept the same as in the previous day, during conditioning. For delay conditioning, mice were monitored, and freezing was measured for the context for $5 \mathrm{~min}$ and for trace conditioning $10 \mathrm{~min}$. The next day, the conditioning room was illuminated with regular white light, and the conditioning chambers were kept lit with infrared light only. The metal grid floors within the conditioning chambers were replaced with smooth plastic flooring, the chambers were wiped with a mild smelling detergent, and some paper items were fixed to the inner walls of the chambers. In this unfamiliar context, for both delay and TFC, mice underwent identical trials to the conditioning day, except no US was given. Freezing in delay fear conditioning was measured in response to the cue. In TFC, freezing response during the first $5 \mathrm{~min}$ period was used as baseline, average freezing across all ten, $10 \mathrm{~s}$ tones was used for cue elicited response, and subsequent $20 \mathrm{~s}$ after tone-off interval average freezing was used for the trace elicited response. Freezing in both delay and TFC was measured using Freeze Frame software (Actimetrics). Freezing was defined as the minimum movement necessary for respiration.

Novel object recognition. Mice were handled once a day for a week following a minimum of 1 week acclimatization to the animal facilities, and were kept in groups of 2-5. Mice were then placed individually into a taxi cage and brought to the novel object recognition (NOR) room, and left in the cage for $10 \mathrm{~min}$ to settle. They were then placed in a $50 \times$ $50 \mathrm{~cm}$ open field arena (Noldus Information Technology), and over the course of $10 \mathrm{~min}$ they were acclimatized to the arena. The following day, the mice were returned to the arena, in which two similar objects were placed, and were allowed to explore the objects for $10 \mathrm{~min}$. The next day, one of the objects was replaced with a novel object, and the mice were placed within the arena, and once again given $10 \mathrm{~min}$ to explore both objects. Mouse movement was captured using an Ikegami ICD-49E camera, and snout position was monitored throughout the $10 \mathrm{~min}$ exploration period and analyzed with EthoVision 14 software (Noldus Information Technology). In order to measure preference for the novel object, a discrimination index was calculated thus: (time exploring novelty - time exploring old)/(time exploring novelty + time exploring old).

Novel context incidental learning. Mice were taken from home cages to a novel cage fitted with a metal grid floor, striped walls, white ceiling and scented lightly with a window cleaning detergent underneath the 
metal grid flooring. They were kept in this cage for $15 \mathrm{~min}$, and returned to their home cage where they were kept for 1 or $3 \mathrm{~h}$ before being killed, to quantify miR-182 or QR2. For pharmacological studies using scopolamine, eticlopride, or SCH23390 (R(+)-7-chloro-8-hydroxy-3-methyl1-phenyl-2,3,4,5-tetrahydro-1H-3-benzazepine hydrochloride, Sigma Millipore), mice were first familiarized with intraperitoneal injections by injecting saline 4 times before experimentation. Saline injections were conducted every $2 \mathrm{~d}$, and then 2-4 d later the experiment was conducted, using the same novel context cage described above.

\section{Pharmacology}

Materials. Dopamine D2 receptor antagonist eticlopride and D1 receptor SCH23390 (Sigma Millipore) were dissolved in saline (0.9\%) and injected $(0.05 \mathrm{mg} / \mathrm{kg}$, i.p.). Muscarinic acetylcholine receptor antagonist scopolamine (Sigma Millipore) was injected ( $2 \mathrm{mg} / \mathrm{kg}$, i.p.). All antagonists were given $40 \mathrm{~min}$ before experimentation. QR2 inhibitor S29434 was synthesized (INCPM, Weizmann Institute of Science), dissolved in DMSO and diluted to a final concentration of $36 \mu \mathrm{M}, 0.5 \%$ DMSO in saline.

Cannula implantations and drug microinjections. Animals were anesthetized under 2\% isoflurane, using an induction box (HME109, Highland Medical Equipment). They were placed in a stereotaxic device (Kopf Stereotaxic Alignment System, model 1900) under continuous 1\% isoflurane anesthesia. Guide cannulas were implanted bilaterally to CA1 (from bregma: $-1.9 \mathrm{~mm} \mathrm{AP,} \pm 1.4 \mathrm{~mm} \mathrm{ML},-1.6 \mathrm{~mm} \mathrm{DV}$ ), cemented to the skull and fitted with 28 -gauge dummy cannulas extending $0.2 \mathrm{~mm}$ beyond the tip of the $1.2 \mathrm{~mm}$ guide cannulas. Following the operation, the mice were allowed at least $7 \mathrm{~d}$ of recovery before experimentation. QR2 inhibitor S29434 or vehicle (0.5\% DMSO in $0.9 \%$ saline) were delivered to CA1 directly, via a 28-gauge infusion cannula projecting $0.4 \mathrm{~mm}$ (drug delivery depth bregma: $-1.6 \mathrm{~mm} \mathrm{DV}$ ) beyond the guide cannula, connected by polyethylene tubing to a $10 \mu$ l syringe (Hamilton). S29434 $36 \mu \mathrm{M}$ or vehicle was delivered in $1 \mu \mathrm{l}$ doses over the course of $1 \mathrm{~min}$. The injection cannula was kept in the guide cannula for a further $60 \mathrm{~s}$ to prevent osmotic seepage of the doses upward through the cannula tract. Twenty minutes later, animals underwent fear conditioning. Following experimentation, animals were killed, brains were sliced in coronal sections, and cannula implantation was validated by imaging.

\section{Viral vectors and transduction}

Recombinant lentiviral vector production. Transient cotransfection of four endotoxin-free plasmids (Endo Free plasmid Maxi kit, catalog \#12362, QIAGEN) in HEK293FT (Invitrogen) cells produced self-inactivating, third-generation HIV-1-based viral vectors (Tiscornia et al., 2006). pLenti-miR182-GFP and pLenti-control-GFP, as well as short hairpin RNA (shRNA) constructs targeting QR2 and a scrambled control (Rappaport et al., 2015) transfer plasmids were purchased from Applied Biological Materials. Cells were kept in a humidified $37^{\circ} \mathrm{C}$ incubator with $5 \% \mathrm{CO}_{2}$ in DMEM with $10 \%$ FBS (Invitrogen), penicillin $(100 \mathrm{IU} / \mathrm{ml})$, and streptomycin $(100 \mathrm{mg} / \mathrm{ml})$. Transfection was done using polyethyleneimine (Signagen), according to the manufacturer's protocol. Cell culture medium was replaced 30 min before transfection; and following $17 \mathrm{~h}$ of incubation, the medium was again replaced with DMEM, supplemented with $10 \%$ FBS. Medium was harvested $48 \mathrm{~h}$ after transfection and cleared by using low-speed centrifugation (800 RCF, $10 \mathrm{~min}$, at $4^{\circ} \mathrm{C}$ ), and was filtered with $0.45 \mu \mathrm{m}$ pore filters (Nunc). Vectors were concentrated via ultracentrifugation with a SW28 rotor (Beckman Coulter; 19,000 RPM, $2.5 \mathrm{~h}, 15^{\circ} \mathrm{C}$ ), and the resultant pellets were then suspended in HBSS (Sigma Millipore) and stored at $-80^{\circ} \mathrm{C}$. Vectors were titrated by HEK293FT transduction, using serial dilutions of the viral vector stock, along with $8 \mu \mathrm{g} / \mu \mathrm{l}$ of Polybrene (Sigma Millipore). GFP expression was then analyzed by flow cytometry following $2 \mathrm{~d}$. The obtained titer was $108 \mathrm{Tu} / \mathrm{ml}$.

$A A V$ plasmids and production of recombinant $A A V$ vectors. pAAVSico-Red was a gift from Eun Mi Hwang (Addgene plasmid \#84882; http://n2t.net/addgene:84882; RRID:Addgene_84882). Relevant shRNA sequences (shNQO2 and scrambled control) were cloned into pAAVSico-Red using conventional cloning techniques. AAV p315 (ssAAV-1/2mCaMKII $\alpha$-EGFP_2A_iCre-WPRE-SV40p(A), physical titer $4.6 \times 10^{12}$ $\mathrm{vg} / \mathrm{ml}$ ) for the expression of Cre regulated by the CamKII promoter, AAV p104 (ssAAV-8/2-hEF1 $\alpha$-dlox-hM4D(Gi)_mCherry(rev)-dloxWPRE-hGHp(A), physical titer $2.9 \times 10 \mathrm{E} 12 \mathrm{vg} / \mathrm{ml}$ ) for the Cre-dependent expression of hM4Di and AAV p114 (ssAAV-8/2-hEF1 $\alpha$ dlox-mCherry(rev)-dlox-WPRE-hGHp(A), physical titer $6.8 \times 10 \mathrm{E} 12$ $\mathrm{vg} / \mathrm{ml}$ ) for the Cre-dependent expression of mCherry were purchased from the University of Zurich Viral Vector Facility (https://vvf.ethz.ch/).

To produce AAV vectors, HEK293FT cells were seeded at 25\%-35\% confluence. The cells were transfected $24 \mathrm{~h}$ later with plasmids encoding AAV rep, cap of AAV1 and AAV2, and a vector plasmid for the rAAV cassette expressing the relevant shRNA using the PEI method (Grimm et al., 2003). Cells and medium were harvested $72 \mathrm{~h}$ after transfection, pelleted by centrifugation $(300 \times g)$, resuspended in lysis solution $(150 \mathrm{~mm}$ $\mathrm{NaCl}, 50 \mathrm{~mm}$ Tris- $\mathrm{HCl}, \mathrm{pH} 8.5$, with $\mathrm{NaOH}$ ), and lysed by three freezethaw cycles. The crude lysate was treated with $250 \mathrm{U}$ benzonase nuclease (Sigma Millipore) per $1 \mathrm{ml}$ of lysate at $37^{\circ} \mathrm{C}$ for $1.5 \mathrm{~h}$ to degrade genomic and unpackaged AAV DNA. The crude lysate was then centrifuged at $3000 \times g$ for $15 \mathrm{~min}$ to pellet cell debris. The virus particles in the supernatant were purified using heparin-agarose columns, washed with PBS, and concentrated by Amicon columns. Viral suspension was aliquoted and stored at $-80^{\circ} \mathrm{C}$. Viral titers were determined using real-time PCR. $\mathrm{AAV}$ vectors used for injections had genomic titers ranging between $2 \times$ $10^{10}$ and $5 \times 10^{10}$ genome copies per $\mathrm{ml}(\mathrm{gc} / \mathrm{ml})$.

\section{Surgeries and virus injection}

Animals were anesthetized using ketamine and Domitor $(0.5 \mathrm{mg} / \mathrm{kg}$ each, i.p.), and given Norocarp $0.5 \mathrm{mg} / \mathrm{kg}$ i.p.; $40 \mathrm{~min}$ later, they were affixed onto a robotic stereotaxic device (Neurostar). The skull was exposed via an AP scalp incision. Referencing bregma and $\lambda$, drilling and injection site coordinates were defined (for dorsal CA1, bregma: AP $-1.78 \mathrm{~mm}, \mathrm{ML} \pm 1.2 \mathrm{~mm}$, DV $1.6 \mathrm{~mm}$; for LC, bregma: AP $-5.25 \mathrm{~mm}$, $\mathrm{ML} \pm 0.88 \mathrm{~mm}, \mathrm{DV} 2.71$ ); and once the syringe (Hamilton) was in place, it was kept still at the injection site for $5 \mathrm{~min}$ before virus injection. Once initiated, $0.25-0.8 \mu \mathrm{l}$ of virus was injected at a rate of $0.05 \mu \mathrm{l} / \mathrm{min}$ using StereoDrive and InjectoMate software (Neurostar). Upon completion, the syringe was left in the injection site for an additional $10 \mathrm{~min}$ to avoid virus retraction. The mice were then given at least a week to recover from the operation, and then a further week to a month time to ensure viral expression was fully achieved.

\section{Brain dissection and tissue preparation}

For Western blot or qPCR analysis, following death by cervical dislocation, mice brains were immediately removed and flash frozen with liquid nitrogen. Brains were stored at $-80^{\circ} \mathrm{C}$ and then transferred to a cryostat (CM 1950, Leica Microsystems), whereupon they were equilibrated to $-15^{\circ} \mathrm{C}$. CA1 samples were removed from $0.5-\mathrm{mm}$-thick coronal slices (from bregma: AP $-1.355 \mathrm{~mm}$, to bregma: AP $-2.48 \mathrm{~mm}$ ) (Franklin and Paxinos, 2008) with the use of a tissue punching device, while control aIC samples were taken as previously described (Gould et al., 2020). For DAT Cre mice LC inactivation experiments, brains were removed and split with a coronal cut, separating the dorsal hippocampus and LC containing anterior and posterior parts of the brain. The posterior, LC containing portion was immersed in $4 \%$ PFA for further processing (cut to $50 \mu \mathrm{m}$ sagittal slices for imaging of infected dopaminergic neurons of the LC), while the anterior, dorsal CA1 containing portion was kept at $-80^{\circ} \mathrm{C}$, until transferred to the cryostat for tissue dissection as detailed above.

\section{Western blot}

Kv2.1 cysteine oxidation and subsequent channel oligomerization were measured as previously described (Cotella et al., 2012). Samples were mechanically homogenized in nonreducing lysis buffer (HEPES $10 \mathrm{~mm}$, EGTA $2 \mathrm{~mm}$, EDTA $2 \mathrm{~mm}, 1 \times$ protease inhibitor cocktail, and $1 \times$ phosphatase inhibitor cocktail 3, Sigma Millipore). Protein determination was done with BCA Protein Assay Kit (GE Healthcare). Sample buffer containing $8 \%$ SDS was used to dilute the lysate to $1 \mu \mathrm{g}$ protein per $1 \mu \mathrm{l}$, and no reducing agents, such as $\beta$-mercaptoethanol, were added. Samples $(15 \mu \mathrm{l})$ were then loaded into $4 \%-20 \%$ Mini-PROTEAN TGX Stain Free Gels (Bio-Rad), were electrophoresed, and transferred to 
PVDF membranes. Membranes were then blocked for $2 \mathrm{~h}$ in blocking buffer (Bio-Rad) and incubated with mouse monoclonal Kv2.1 antibody (1:500; University of California at Davis/National Institutes of Health NeuroMab) overnight. The following day, the membranes were incubated with anti-mouse HRP-conjugated antibodies at room temperature for $1 \mathrm{~h}$ (1:10,000; Millipore Bioscience Research Reagents), and immunoblotted with Westar Supernova (Cyangen). Images were captured using a charge-coupled device camera, and analysis was done with Quantity One software (Bio-Rad). Oxidation-dependent oligomerization of Kv2.1 was calculated by using the ratio of oligomeric $(\sim 200 \mathrm{kDa})$ to monomeric $(\sim 100 \mathrm{kDa}) \mathrm{Kv} 2.1$. For quantitating total Kv2.1 expression, $\beta$-mercaptoethanol was first added to the loading buffer, and the samples were boiled for $5 \mathrm{~min}$ at $100^{\circ} \mathrm{C}$. Kv2.1 was then quantified by normalizing to actin (chicken pAb13822, 1:1000; Abcam). Statistical analysis was done using GraphPad Prism 7 software.

\section{$R N A$ extraction, reverse transcription, and $q P C R$}

RNA extraction. Samples were homogenized in Tri reagent $(300 \mu 1$ per $1 \mathrm{~mm}^{3}$ sample), and 1-bromo, 3-chloropropane was added at 1/10 volume of Tri Reagent (Sigma Millipore) and mixed. Chilled centrifugation at $4^{\circ} \mathrm{C}$ for $15 \mathrm{~min}$ at $12,000 \mathrm{RCF}$ was done to separate phases and 2propanol was added in equal volume to the RNA phase, which was collected in new tubes, and mixed thoroughly. A $30 \mathrm{~min} 4^{\circ} \mathrm{C}$ centrifugation at 12,000 RCF followed, resulting in an RNA pellet, which was washed using $300 \mu \mathrm{l}$ of chilled $75 \%$ ethanol. An additional $4^{\circ} \mathrm{C}$ centrifugation of 10 min at 7600 RCF resulted in an RNA pellet, which was air dried and solubilized in $30 \mu \mathrm{l}$ ultra-pure water (Biological Industries).

Reverse transcription and $q P C R$. cDNA was generated using Applied Biosystems (Thermo Fisher Scientific) High Capacity cDNA Reverse Transcription kit. The resultant cDNA was then used in TaqMan (Thermo Fisher Scientific) gene expression assays for QR2 (mouse, Mm01332867_m1), GAPDH (Mm99999915_g1), and HPRT (Mm00446968_m1) primers. For miR-182 expression, TaqMan MicroRNA reagents were used (002599), and quantification was done relative to U6 (001973). Relative quantitation was done by calculating $2^{-\Delta \Delta \mathrm{Ct}}$ of the target genes in the samples (Livak and Schmittgen, 2001). Statistical analysis was done using GraphPad Prism 7 software.

RNAscope and image processing

Fresh frozen brains from mice that had been exposed to a novel context or kept in home cages and were then killed $3 \mathrm{~h}$ later were sliced into $20 \mu \mathrm{m}$ sections in a CM 1950 cryostat (Leica Microsystems) and mounted directly to SuperFrost Ultra Plus Adhesion slides (Thermo Fisher Scientific). RNAscope (ACD) protocol was conducted as per the manufacturer's instructions. Probes used were GAD, vGlut, and QR2, in multiplex on each slice. Upon RNAscope protocol completion, ProLong Gold anti-fade reagent (Thermo Fisher Scientific) was used to mount the cover slides. Slides were allowed to dry overnight in the dark at room temperature. They were then stored at $4^{\circ} \mathrm{C}$ in a protective slide box for a further day at least. Images were obtained using an Olympus IX81 microscope, using Cell Sense software. Images were acquired as a $z$ stack of three layers, each $1.5 \mu \mathrm{m}$ apart. Images were then deconvoluted to remove background, nonspecific signals. Images were then exported as BigTIFF files; and using the ImageJ-based FIJI imaging software, ROIs were manually drawn to denote CA1 subregions, according to the mouse brain atlas (Franklin and Paxinos, 2008). Images for probes requiring further background noise reduction were cleaned using the BioVoxxel convoluted background subtraction FIJI plugin and converted into binary masks. GAD masks were subtracted from vGlut and DAPI to prevent double counting. Using the FIJI Analyze Particles function within the CA1 ROI, cells were selected, and an ROI was generated for each cell within the subregion. QR2 was then measured within these cell ROI. This was done using the FIJI Command Manager "Measure" function. This provides a QR2 signal mean within each cell type, with each QR2 particle represented as a binary value of 255 and any non-QR2 area as a 0 value. A list of mean QR2 scores was then saved for each subregion for each slice from both hemispheres in an Excel file. An average of the familiar context, control group's QR2 signal was calculated, and the QR2 measurement for each individual cell in familiar and novel context groups was then divided by this average, allowing total neuronal QR2 expression comparison. To compare QR2 expression in either excitatory or inhibitory neurons, the same procedure was conducted with each set of cells separately. For relative contribution of each cell type to the QR2 signal, cells were binned into either vGlut-positive or GAD-positive in both familiar and novel context. Total signal of each cell type (normalized to familiar context average signal) was divided by total cell number within each experimental group. The contribution to the reduction in QR2 signal was calculated by deducting novel context QR2 signal of each cell type from that of familiar context. Statistical analysis was then done using GraphPad Prism 7 software.

\section{Electrophysiology}

Tissue preparation. Mice were killed by decapitation following anesthesia with isoflurane. Briefly, $300 \mu \mathrm{m}$ coronal brain slices were prepared with a vibratome (Campden-1000) in ice-cold cutting solution (sucrose $110 \mathrm{~mm}, \mathrm{NaCl} 60 \mathrm{~mm}, \mathrm{KCl} 3 \mathrm{~mm}, \mathrm{NaH}_{2} \mathrm{PO}_{4} 1.25 \mathrm{~mm}, \mathrm{NaHCO}_{3} 28 \mathrm{~mm}$, $\mathrm{CaCl}_{2} 0.5 \mathrm{~mm}, \mathrm{MgCl}_{2} 7 \mathrm{~mm}, \mathrm{D}$-glucose $5 \mathrm{~mm}$, and ascorbate $0.6 \mathrm{~mm}$, Sigma Millipore). The slices were then kept for a recovery period of $30 \mathrm{~min}$ at $37^{\circ} \mathrm{C}$ in ACSF $\left(\mathrm{NaCl} 125 \mathrm{~mm}, \mathrm{KCl} 2.5 \mathrm{~mm}, \mathrm{NaH}_{2} \mathrm{PO}_{4} 1.25 \mathrm{~mm}\right.$, $\mathrm{NaHCO}_{3} 25 \mathrm{~mm}$, D-glucose $25 \mathrm{~mm}, \mathrm{CaCl}_{2} 2 \mathrm{~mm}$, and $\mathrm{MgCl}_{2} 1 \mathrm{~mm}$, Sigma Millipore) and then moved to room temperature for an additional $30 \mathrm{~min}$ at least, before electrophysiological recording. ACSF was continually gassed with carbogen $\left(\mathrm{O}_{2} 95 \%, \mathrm{CO}_{2} 5 \%\right)$ throughout.

Intracellular whole-cell recording. Measurement of active intrinsic properties was done as previously reported (Chakraborty et al., 2017). After a $1 \mathrm{~h}$ recovery period in ACSF, the slices were placed in a recording chamber, and kept at $32^{\circ} \mathrm{C}-34^{\circ} \mathrm{C}$ with a continuous wash of carbogenated ACSF $(2 \mathrm{ml} / \mathrm{min}$ ) throughout the recording. CA1 pyramidal cells were visualized with differential interference contrast microscopy (Olympus BX51-WI), using $10 \times$ or $40 \times$ water immersion objectives. Images were captured on a monitor using a charge-coupled device camera (Dage MTI). For GABAergic, Cre-expressing interneurons, Cre-dependent mCherry reporter protein expression was used to identify and distinguish the cells. Recording amplification was done with Multiclamp Axopatch 200B amplifiers and was digitized using Digidata 1440 (Molecular Devices). Recording electrodes were pulled from a borosilicate glass pipette (3-5 M), with a P-1000 electrode puller (Sutter Instruments) and then filled with 290 mOsm, pH 7.3 internal solution (K-gluconate $130 \mathrm{~mm}, \mathrm{KCl} 5 \mathrm{~mm}$, HEPES $10 \mathrm{~mm}, \mathrm{MgCl}_{2} 2.5 \mathrm{~mm}$, EGTA $0.6 \mathrm{~mm}, \mathrm{Mg}$-ATP $4 \mathrm{~mm}, \mathrm{Na}_{3} \mathrm{GTP} 0.4 \mathrm{~mm}$, and phosphocreatine $10 \mathrm{~mm}$, Sigma Millipore). Recordings were made from the soma of pyramidal cells and interneurons expressing mCherry, in the CA1 region of C57BL/6 and GAD-Cre mice with S29434 (0.5\% DMSO) or vehicle in the patch pipette. Liquid junction potentials $(10 \mathrm{mV})$ were not corrected online, and the current-clamp recordings made were all low-pass filtered at $10 \mathrm{kHz}$ and sampled at $50 \mathrm{kHz}$. Compensation for pipette capacitance and series resistance was done, and only cells with resistance $<20 \mathrm{M} \Omega$ were included.

Recording parameters. After $10 \mathrm{~s}$ of whole-cell recording commencement, resting membrane potential was measured by rupturing the membrane directly under the recording pipette $(<-40 \mathrm{mV})$. Injection of current steps of $500 \mathrm{~ms}$ duration, from 50 to $450 \mathrm{pA}$ in $50 \mathrm{pA}$ increments were used to measure the cell firing rate (current-clamp mode, holding at $-70 \mathrm{mV}$ ). The voltage response to a hyperpolarizing current pulse $(-150 \mathrm{pA})$ was used to calculate the input resistance. The sag ratio was calculated by $\left[\left(1-\Delta \mathrm{V}_{\mathrm{SS}} / \Delta \mathrm{V}_{\max }\right) \times 100 \%\right]$ of the voltage response to $-150 \mathrm{pA}$, as previously determined (Song et al., 2015). Single exponential fit of the first $100 \mathrm{~ms}$ of the raising phase of the cell response to a $500 \mathrm{~ms},-150 \mathrm{pA}$ hyperpolarization step enabled the determination of the membrane time constant.

A series of brief depolarizing currents were injected for $10 \mathrm{~ms}$ in steps of $10 \mathrm{pA}$ increments to measure single action potentials, after an initial assessment of the current needed to cause an action potential $15 \mathrm{~ms}$ from the start of the current injection with $50 \mathrm{pA}$ steps was done. The first action potential that appeared, at $5 \mathrm{~ms}$, was analyzed. A dV/dt curve was made for that action potential trace, and the $30 \mathrm{~V} / \mathrm{s}$ point in the rising slope of the action potential was considered as threshold 
a

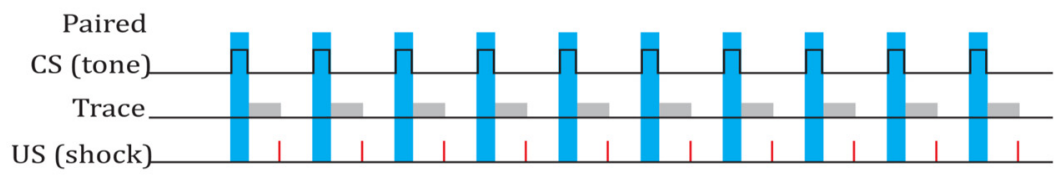

C
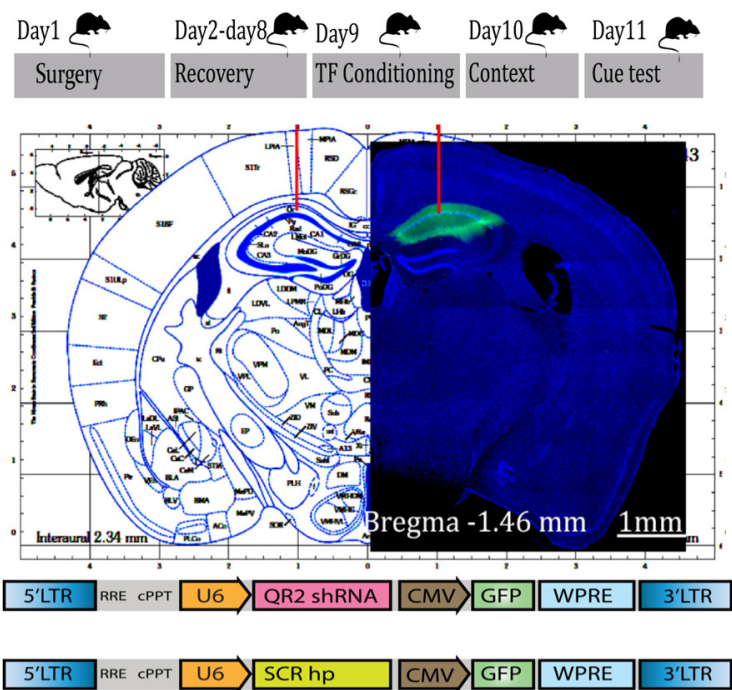

b

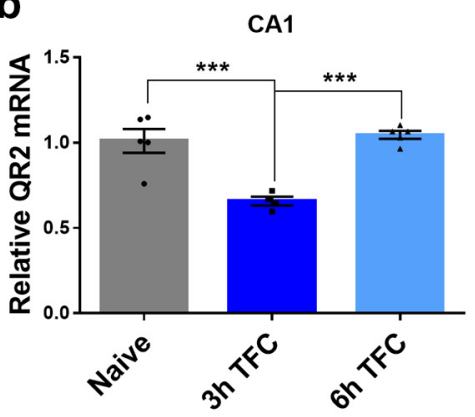

e

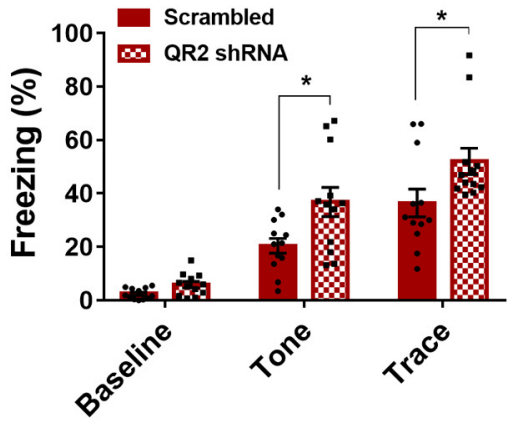

f

-20min -10 min 0 min 10 min 20 min 30 min 40 min $50 m i n$

QR2i/Vehicle Trace Fear Conditioning(TFC)

Local Injections g

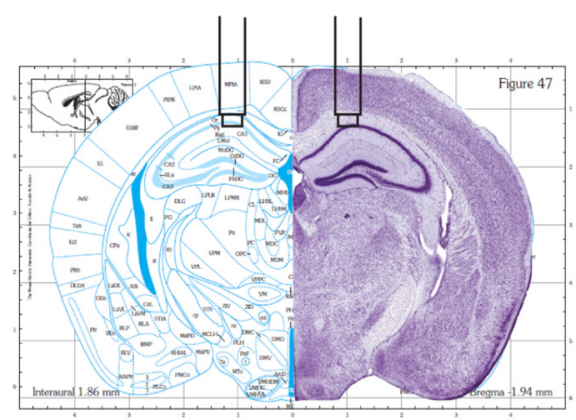

i

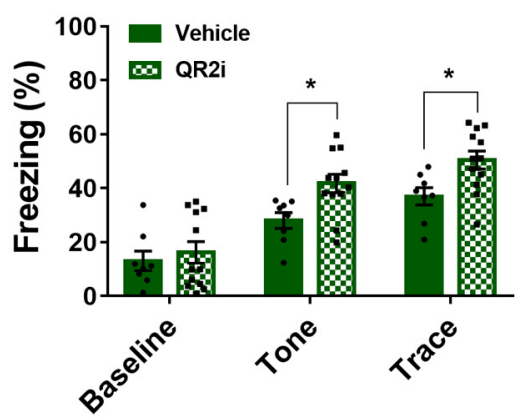

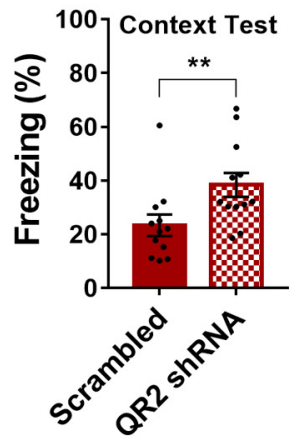

h
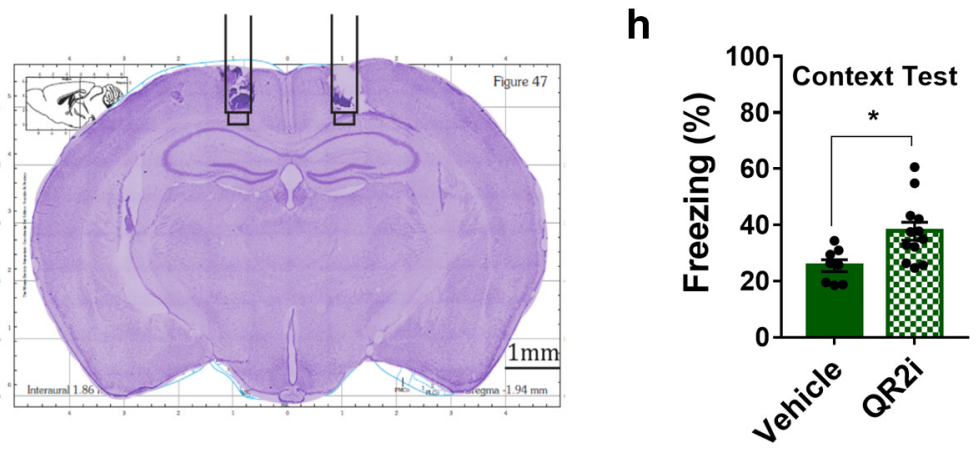

Figure 1. QR2 inhibition or reduced expression in CA1 improves TFC memory. $\boldsymbol{a}$, Mice underwent TFC, which involves 5 min exploration followed by 10 trials in which a tone is applied for $10 \mathrm{~s}$, followed by a footshock $20 \mathrm{~s}$ later and an intertrial interval of $3.5 \mathrm{~min}$. $\boldsymbol{b}$, Mice were killed 3 or $6 \mathrm{~h}$ following TFC, and QR2 mRNA levels were measured and compared with mice that were kept in their familiar home cages. Mice that experienced TFC showed a significant reduction in QR2 mRNA expression in CA1 only $3 \mathrm{~h}$ later (Naive $1.011 \pm 0.0692^{-} \Delta \Delta \mathrm{Ct}, n=5 ; 3 \mathrm{~h}$ TFC $0.657 \pm 0.0252^{-\Delta \Delta \mathrm{Ct}}, n=4 ; 6 \mathrm{~h}$ TFC $1.046 \pm 0.0232^{-\Delta \Delta \mathrm{Ct}} ;$ one-way ANOVA, $F_{(2,11)}=18.7, p=0.0003$; Tukey's multiple comparisons post hoc test, Naive vs $3 \mathrm{~h}$ TFC, $p=0.0009 ;$ Naive vs $6 \mathrm{~h} \mathrm{TFC}, p=0.851 ; 3 \mathrm{~h}$ TFC vs $6 \mathrm{~h} \mathrm{TFC}, p=0.0004)$. c, Mice were injected with a lentivirus-expressing shRNA targeting QR2 mRNA or a scrambled control to CA1 and underwent TFC. $\boldsymbol{d}$, Mice 
(Chakraborty et al., 2017). Action potential duration was measured at the point of half-amplitude of the spike, and amplitude was measured from the equipotential point of the threshold to the spike peak. The medium afterhyperpolarization was measured using prolonged $3 \mathrm{~s}, 3 \mathrm{nA}$ high amplitude somatic current injections, to initiate a time-locked action potential train at $50 \mathrm{~Hz}(10-50 \mathrm{~Hz}, 1$ or $3 \mathrm{~s})$ in the cells. The action potential trains generated caused a prolonged (20 s) afterhyperpolarization, the amplitudes and integrals of which increased proportionally to the number of action potentials in the spike train. The afterhyperpolarizations were measured from the equipotential point of the threshold, to the antipeak of the same spike (Gulledge et al., 2013). Membrane capacitance, series resistance, and input resistance were monitored during the duration of the experiment, with any changes in these parameters $>30 \%$ leading to exclusion of the data.

Experimental design and statistical analysis

Male subjects were randomly allocated to different experimental groups and their controls. Group size estimation was based on our previously published results that used similar methods as reference, and the use of an online power calculator (https://www.stat.ubc.ca/ $\sim$ rollin/stats/ssize/n2.html). Normally distributed (assessed with Shapiro-Wilk normality tests) data were analyzed using Student's $t$ test, one-way ANOVA, or repeated-measures two-way ANOVA followed by Tukey's or Sidak's post hoc analysis. For data not normally distributed, or data that first required normalization before analysis (see RNA scope), nonparametric Mann-Whitney test or KruskalWallis followed by Dunn's multiple comparisons test was used. All data are presented as mean \pm SEM. All descriptive statistics, normality tests, and parametric and nonparametric tests were conducted using GraphPad Prism 7 software.

\section{Results}

QR2 inhibition or reduced expression in CA1 improves trace fear conditioning memory

We have previously shown that QR2 expression in the rodent aIC is reduced $3 \mathrm{~h}$ following novel taste consumption (Rappaport et al., 2015). We therefore wished to assess whether QR2 reduction is pivotal also in hippocampal-dependent memory consolidation. For this purpose, we used the TFC paradigm, which relies on the dorsal hippocampus for the formation of memory of a novel context and its associated tone and trace (Fig. 1a) (Raybuck and Lattal, 2011). Unlike delay fear conditioning, in TFC there is a long (20 s) gap between the end of the CS (tone) and US

receiving shRNA directed against QR2 showed significantly better contextual memory, indicated by the increased freezing (Scrambled 23.36 $\pm 3.975 \%, n=12$; QR2 shRNA $38.41 \pm 4.471 \%, n=12$; Mann-Whitney test, $p=0.0068)$. $\boldsymbol{e}$, Mice injected with shRNA to QR2 displayed better memory to the cue (Scrambled 20.39 $\pm 2.76 \%, n=12$; QR2 shRNA $36.85 \pm 5.474 \%, n=12$; Student's $t$ test, $t=2.685, \mathrm{df}=22, p=0.0135$ ) and trace (Scrambled $36.41 \pm 5.179 \%, n=12$; QR2 shRNA $52.04 \pm 4.942 \%, n=12$; Mann-Whitney test, $p=0.0145$ ), compared with controls. $f$, Mice were cannulated to CA1 and were given QR2 inhibitor S29434 (36 $\mu \mathrm{M})$ or vehicle and 20 min later underwent TFC. $\boldsymbol{g}$, Cannula placement in mice undergoing TFC with S29434 or vehicle control. $\boldsymbol{h}$, Mice that received S29434 froze significantly more than those receiving vehicle, displaying improved contextual memory (Vehicle 25.46 $\pm 2.128 \%, n=8$; $52943437.73 \pm 3.22 \%, n=12$; Student's $t$ test, $t=2.83$, $\mathrm{df}=18, p=0.0111)$. $\boldsymbol{i}$, Cue and trace induced significantly greater freezing in mice receiving S29434, indicating improved memory (Cue test, Vehicle $28.02 \pm 2.905 \%, n=8$; $\$ 29434$ $41.79 \pm 3.395 \%, n=12$; Student's $t$ test, $t=2.865, \mathrm{df}=18, p=0.0103$; Trace test, Vehicle $36.97 \pm 3.196 \%, n=8 ; 52943450.49 \pm 3.338 \%, n=12 ;$ Student's $t$ test $, t=2.78, \mathrm{df}=18$, $p=0.0123)$. $\boldsymbol{j}$, Mice injected with $\$ 29434$ show a significant reduction in Kv2.1 channel oxidation compared with vehicle controls (left, Vehicle $1 \pm 0.037 \mathrm{AU}, n=10$; $\$ 29434$ $0.897 \pm 0.041 \mathrm{AU}, n=11$; Mann-Whitney test, $p=0.0357$ ), as measured by nonreduced Western blot (right, top; $\mathrm{i}=$ S29434; $v$ = Vehicle) and confirmed following addition of reducing agent $\beta$-mercaptoethanol (right, bottom). Data are mean \pm SEM. ${ }^{*} p<0.05$. ${ }^{* *} p<0.01$. ${ }^{* * *} p<0.001$. (footshock). The conditioned memory for the discontiguous CS and US, which are separated by a trace period $(20 \mathrm{~s})$, relies on the dorsal hippocampus rather than the amygdala, and memory for the CS, trace, and context can be measured (Chowdhury et al., 2005). To test whether QR2 mRNA expression was reduced following TFC in CA1 or the BLA, which may be involved in TFC (Kwapis et al., 2011), mice were killed 3 or $6 \mathrm{~h}$ following the conditioning (on day 9) and compared with control mice that did not undergo TFC. A significant reduction in QR2 expression $3 \mathrm{~h}$ following TFC was seen in the CA1 subregion of the hippocampus (Fig. 1b), but not in the BLA (Naive $1.009 \pm 0.0672^{-\Delta \Delta C t}$, $n=5 ; 3$ h TFC $0.921 \pm 0.0572^{-\Delta \Delta \mathrm{Ct}}, n=4$; Student's $t$ test, $t=0.9572, \mathrm{df}=7, p=0.3703$ ) or control aIC (Naive $1.008 \pm 0.064$ $2^{-\Delta \Delta \mathrm{Ct}}, n=5 ; 3 \mathrm{~h}$ TFC $1.101 \pm 0.0862^{-\Delta \Delta \mathrm{Ct}}, n=4$; Student's $t$ test, $t=0.877, \mathrm{df}=7, p=0.4096$ ).

In order to assess the effect of reducing QR2 expression on memory formation, we injected a viral vector expressing QR2 shRNA or a scrambled control to CA1 (Fig. 1c); and following a recovery period allowing the viral vector to express, mice underwent TFC and their memory was evaluated. The group expressing QR2 shRNA in CA1 froze significantly more in response to context (Fig. 1d), tone, and trace (Fig. 1e) compared with control animals, indicating an improved memory of the learned experience. Mice injected with QR2 shRNA were later killed and QR2 mRNA levels were measured, showing a significant reduction in QR2 expression in CA1 compared with controls (Scrambled $1 \pm 0.086$ $2^{-\Delta \Delta \mathrm{Ct}}, n=10$; QR2 shRNA $0.695 \pm 0.1122^{-\Delta \Delta \mathrm{Ct}}, n=10$; Student's $t$ test, $p=0.0369$ ).

In order to assess whether inhibiting the activity of the QR2 enzyme has a similar effect to reduced QR2 mRNA expression, mice were implanted with cannulas to CA1 (Fig. 1 ). They were then given the QR2 inhibitor S29434 (Ferry et al., 2010) (36 $\mu \mathrm{M})$ or vehicle directly to CA1 $20 \mathrm{~min}$ before TFC (Fig. 1f). The inhibition of QR2 resulted in a similar increase in freezing in response to context (Fig. 1h), tone, and trace (Fig. 1i) to mice with QR2 shRNA, implying the QR2 gene product (i.e., the QR2 enzyme) directly as being the cause for the observed memory enhancement. Since the QR2 enzyme has been shown to act as a ROS modulating reductase in the brain (Gould et al., 2020), we assessed how QR2 inhibition would affect CA1. Mice were therefore injected with S29434 (8 mg/kg, i.p.) or vehicle, were killed 4 $\mathrm{h}$ later, and the redox state of CA1 was measured. This can be done by measurement of the redox-sensitive voltage-gated potassium channel Kv2.1, which on oxidation forms disulfide bonds with other Kv2.1 channels. Thus, we measured the ratio of oxidized (oligomeric) to reduced (monomeric) Kv2.1 channels, as previously described (Cotella et al., 2012; Frazzini et al., 2016). We found that QR2 inhibition significantly reduced the oxidation ratio of Kv2.1, indicating a slight reduction in ROS in CA1 (Fig. 1j). Total Kv2.1 expression, however, was unchanged (Vehicle $1 \pm 0.109 \mathrm{AU}, n=10$; S29434 $0.985 \pm 0.060 \mathrm{AU}, n=11$; Mann-Whitney test, $p=0.903)$. QR2 suppression therefore reduces ROS and facilitates novel stimuli consolidation across different brain regions subserving different learning modalities, and its removal enhances subsequent learning.

\section{Novelty of the context reduces QR2 expression via miR-182 upregulation}

In order to determine whether QR2 is similarly sensitive just to the novelty aspect of the context (i.e., the CS itself as incidental information), we took mice from their home cages into novel context cages (see Materials and Methods). After $15 \mathrm{~min}$, they were returned to their home cages and $3 \mathrm{~h}$ later were killed, and 
a

1

\section{Home Cage}

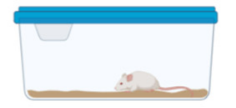

4

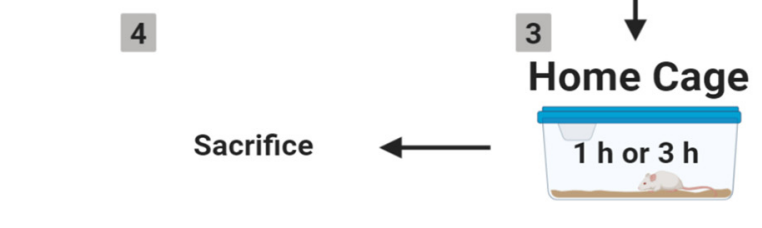

2

\section{Novel Cage}

$15 \mathrm{~min}$
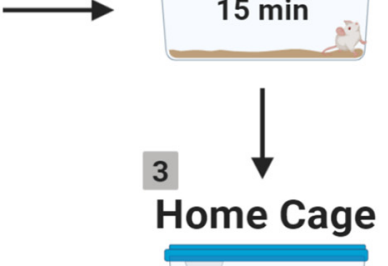

b

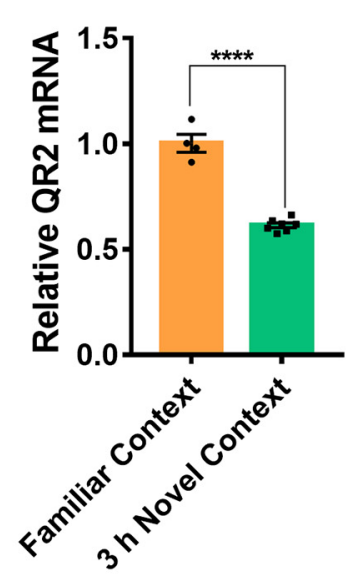

C

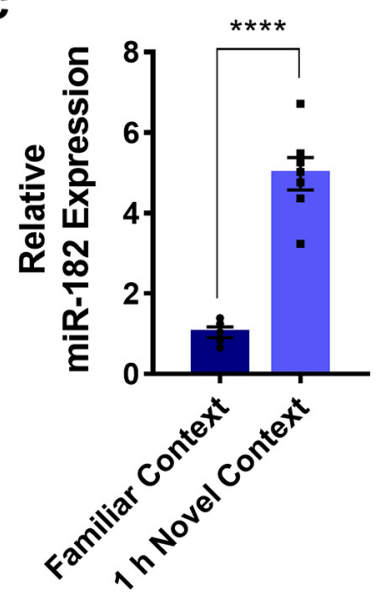

d

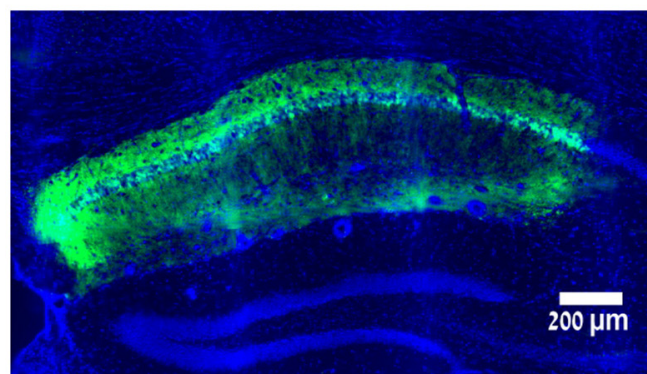

e
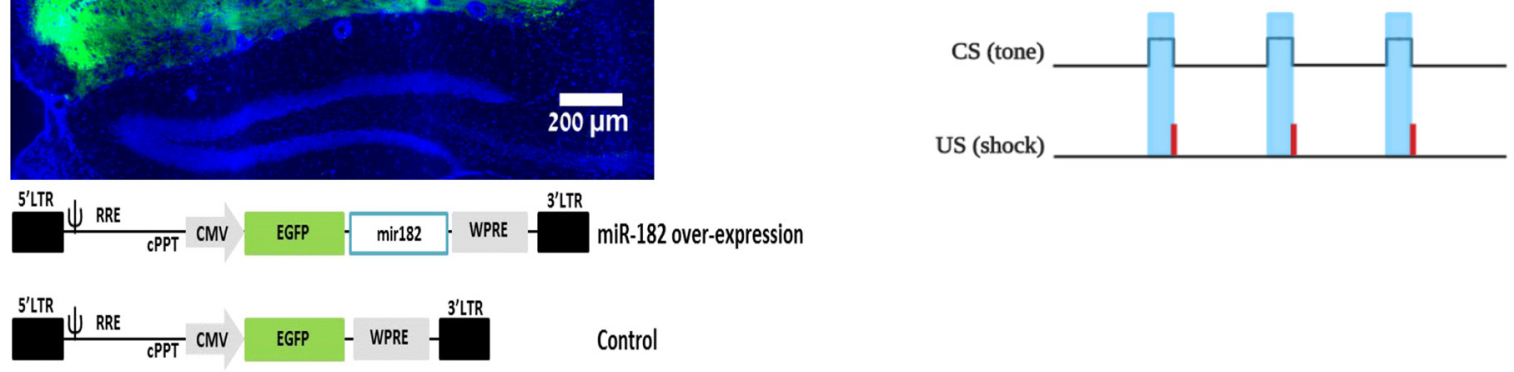

f

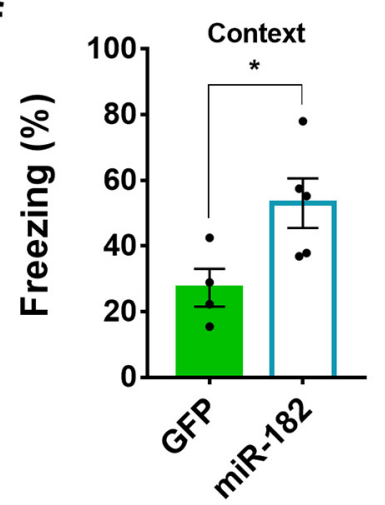

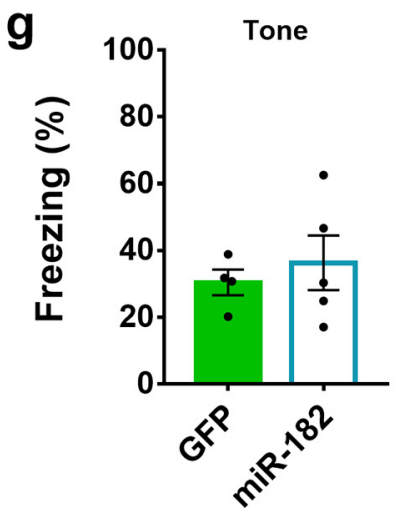

h

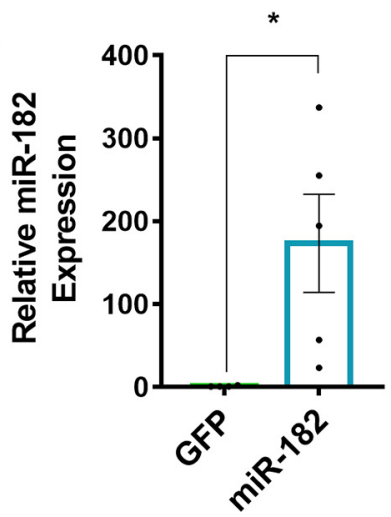

i

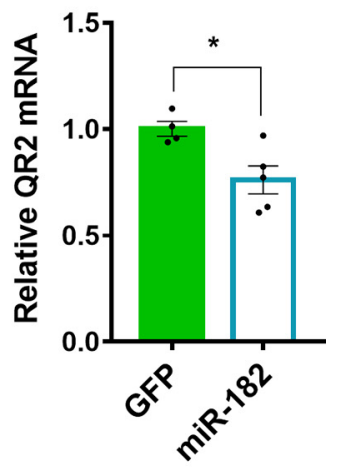

Figure 2. Novelty of the context reduces QR2 expression via miR-182 upregulation. $\boldsymbol{a}$, Mice were taken from their home cage to a novel cage for 15 min, and were then returned to the familiar home cage and killed either 1 or $3 \mathrm{~h}$ later. $\boldsymbol{b}$, Mice exposed to the novel cage and killed $3 \mathrm{~h}$ later showed significantly reduced QR2 mRNA expression in CA1 (Familiar Context $1.003 \pm 0.0112^{-\Delta \Delta \mathrm{ct}}, n=4 ; 3 \mathrm{~h}$ Novel Context $0.613 \pm 0.0112^{-\Delta \Delta \mathrm{ct}}, n=7$; Student's $t$ test, $\left.t=11.33, \mathrm{df}=9, p<0.0001\right)$. c, Mice exposed to the novel cage and killed $1 \mathrm{~h}$ later showed significantly increased miR-182 levels in CA1 (Familiar Context 1.035 $\pm 0.1322^{-\Delta \Delta \mathrm{ct}}, n=5 ; 1 \mathrm{~h}$ Novel Context $4.978 \pm 0.4032^{-\Delta \Delta \mathrm{ct}}, n=7 ;$ Student's $t$ test, $t=7.941, \mathrm{df}=10$, $p<0.0001)$. $\boldsymbol{d}$, A lentivirus-expressing miR-182 and a GFP reporter, or GFP alone, was made and injected to CA1. $\boldsymbol{e}$, The miR-182 and GFP-injected mice underwent delay conditioning. $\boldsymbol{f}$, Contextual memory was significantly improved in mice over expressing miR-182 in CA1 compared with controls (Lenti-GFP 27.32 $\pm 5.772 \%, n=4$; Lenti-miR-182 53.1 $\pm 7.541 \%, n=5$; Student's $t$ test, $t=2.593, \mathrm{df}=7, p=0.0358$ ). $\boldsymbol{g}$, No difference was seen in the freezing of mice over expressing miR-182 compared with controls in response to the cue (Lenti-GFP $30.39 \pm 3.845 \%, n=4$; Lenti-miR-182 36.29 $\pm 8.163 \%, n=5$; Student's $t$ test, $t=0.5989, \mathrm{df}=7, p=0.5681)$. $\boldsymbol{h}$, CA1 of mice injected with miR-182 expressed significantly greater levels of miR-182 compared with controls (Lenti-GFP $1.119 \pm 0.3402^{-\Delta \Delta G t}, n=4$; Lenti-miR-182 $173.4 \pm 59.152^{-\Delta \Delta \mathrm{ct}}, n=5$; Mann-Whitney test, $p=0.015$ ). $\boldsymbol{i}$, QR2 mRNA expression was significantly reduced in the CA1 of miR-182 injected mice (Lenti-GFP $1.002 \pm 0.0352^{-\Delta \Delta \mathrm{Ct}}, n=4$; Lenti-miR-182 $0.761 \pm 0.0662^{-\Delta \Delta \mathrm{Ct}}, n=5$; Student's $t$ test, $t=2.958, \mathrm{df}=7, p=0.0212$ ). Data are mean \pm SEM. ${ }^{*} p<0.05 .{ }^{* * *} p<0.0001$.

QR2 mRNA was measured in CA1 (Fig. 2a). Indeed, QR2 mRNA was significantly reduced in CA1 following novel contextual stimuli alone (Fig. 2b). The control brain region (aIC) did not show any reduction in QR2 mRNA (Familiar Context
$1.002 \pm 0.0342^{-\Delta \Delta \mathrm{Ct}}, n=4 ; 3 \mathrm{~h}$ Novel Context $1.052 \pm 0.039$ $2^{-\Delta \Delta \mathrm{Ct}}, n=7$; Student's $t$ test, $t=0.8532, \mathrm{df}=9, p=0.415$ ).

We have previously shown that miR-182 causes suppression of QR2 mRNA in the aIC (Gould et al., 2020). Since miR-182 is 
a

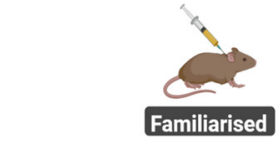

i.p. injection of vehicle or scopolamine / SCH / eticlopride

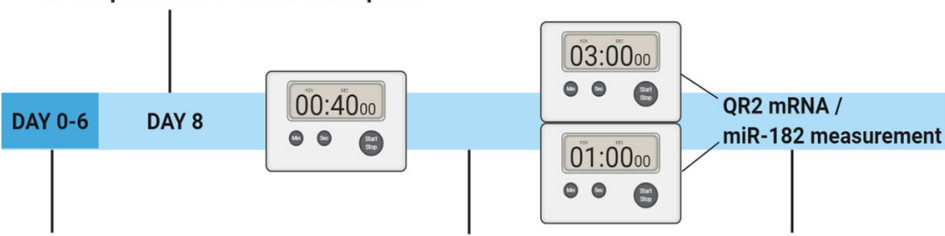

$3 x$ i.p. injection familiarisation using saline every second day

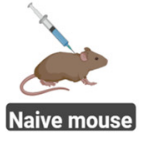

C

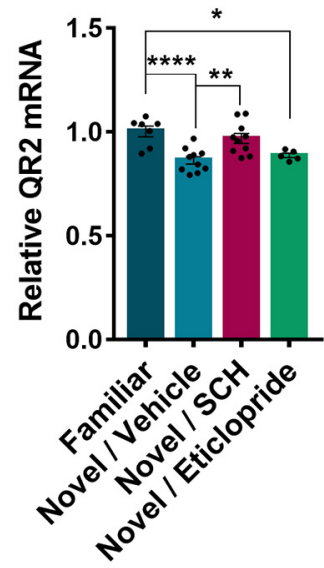

f

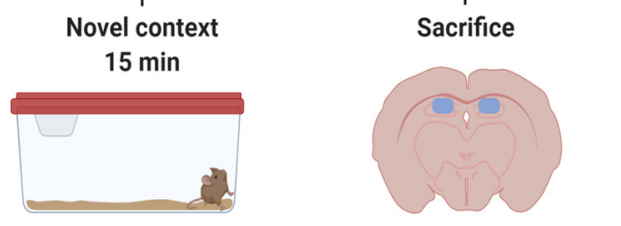

d

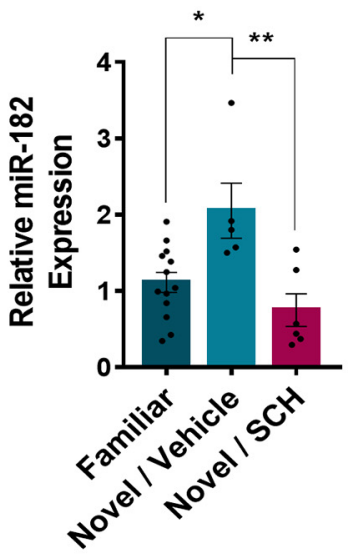

b

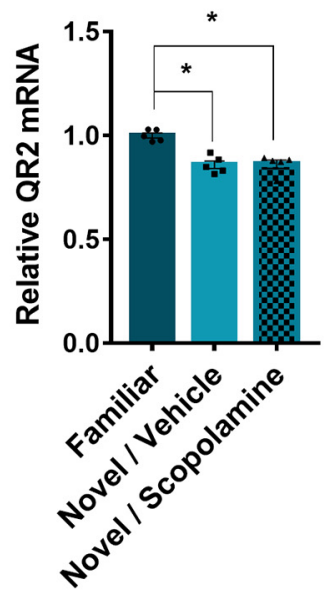

e
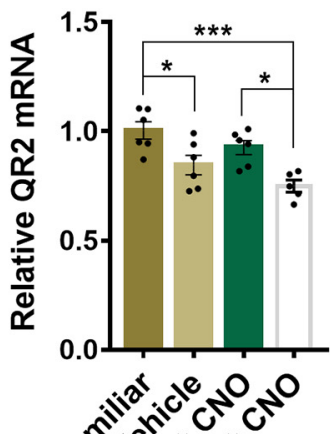

onjex $x \times$

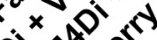

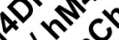
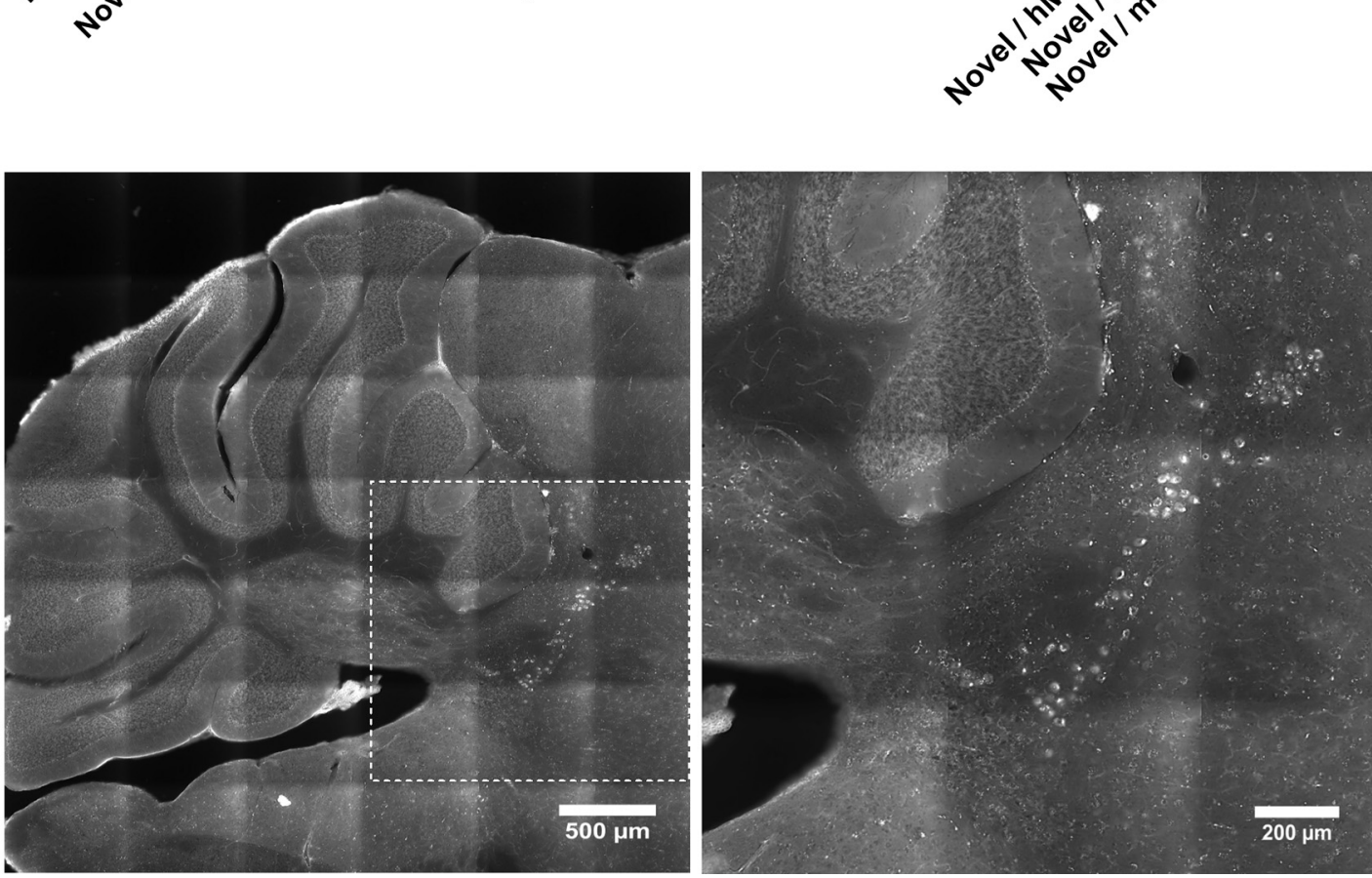

Figure 3. QR2 reduced expression following novel context is D1R- and not D2R- or mAChR-dependent. $\boldsymbol{a}$, Mice were familiarized to intraperitoneal injections, and then were injected scopolamine, eticlopride, $\mathrm{SCH}$, or vehicle. After $40 \mathrm{~min}$, the animals were taken to a novel cage, except one of two groups receiving vehicle. Following 15 min in the novel cage, the animals were returned to their familiar home cages and were killed either 1 or $3 \mathrm{~h}$ later to allow QR2 mRNA or miR-182 measurement in CA1. $\boldsymbol{b}$, QR2 mRNA was significantly reduced in CA1 of mice that received scopolamine or vehicle that were exposed to the novel cage, compared with the control mice kept in familiar home cage (Familiar $1 \pm 0.0122^{-\Delta \Delta \mathrm{ct}}, n=5$; Novel/Vehicle $0.859 \pm 0.0182^{-\Delta \Delta \mathrm{Ct}}, n=5$; Novel/Scopolamine $0.861 \pm 0.022^{-\Delta \Delta \mathrm{ct}}, n=5$; Kruskal-Wallis test, $p=0.0029$; Dunn's multiple comparisons test, Familiar vs Novel/Vehicle, $p=0.0216$; 
known to be upregulated in the hippocampus following novel contextual stimuli (Woldemichael et al., 2016), we aimed to explore whether such miR-182-dependent suppression of QR2 mRNA occurs in CA1 following the novel context paradigm. We therefore killed mice $1 \mathrm{~h}$ following novel context exposure and measured miR-182 at this time point, in which miR-182 has previously shown increased expression following novelty (Jawaid et al., 2019; Gould et al., 2020). In agreement with other studies (Woldemichael et al., 2016; Jawaid et al., 2019), we found a significant increase in miR-182 in CA1 (Fig. 2c), but not in the control brain region (Familiar Context $1.263 \pm 0.4082^{-\Delta \Delta \mathrm{Ct}}, n=4$; $1 \mathrm{~h}$ Novel Context $0.632 \pm 0.1352^{-\Delta \Delta \mathrm{Ct}}, n=6$; Student's $t$ test, $t=1.73, \mathrm{df}=8, p=0.1219)$.

Next, we injected a miR-182-expressing viral vector or control to CA1 (Fig. 2d). We then used delay fear conditioning (Fig. 2e) instead of TFC, which involves the hippocampus for memory of the context and the amygdala for memory of the tone (Raybuck and Lattal, 2011). By thus using delay fear conditioning instead of TFC, we can determine the effect of miR-182 overexpression in CA1 on hippocampal-dependent learning, while the amygdala-dependent memory serves as a control for any non-manipulation-dependent changes in behavior. In agreement with others (Jawaid et al., 2019), we found a significant improvement in contextual memory of mice expressing miR-182 (Fig. 2f) but did not see any effect on amygdala-dependent memory of the tone (Fig. $2 g$ ). The mice were later killed, and measurements showed miR-182 was significantly increased in CA1 (Fig. $2 h$ ) but not the aIC (Lenti-GFP $1.024 \pm 0.1232^{-\Delta \Delta \mathrm{Ct}}, n=4$; Lenti-miR$1821.835 \pm 0.3552^{-\Delta \Delta \mathrm{Ct}}, n=5$; Student's $t$ test, $t=1.942, \mathrm{df}=7$, $p=0.0933$ ), while QR2 was significantly decreased (Fig. $2 i$ ) in CA1, but not in the control aIC (Lenti-GFP $1.004 \pm 0.053$ $2^{-\Delta \Delta \mathrm{Ct}}, \quad n=4$; Lenti-miR-182 $0.921 \pm 0.072 \quad 2^{-\Delta \Delta \mathrm{Ct}}, \quad n=5$; Student's $t$ test, $t=0.8722, \mathrm{df}=7, p=0.4120$ ). These results indicate that during contextual learning a local reduction in QR2 occurs via miR-182 upregulation. In addition, they place QR2 downstream of miR-182 following novel stimuli input, for the stable integration of the newly learned experiences.

\section{$\leftarrow$}

Familiar vs Novel/Scopolamine, $p=0.0267$; Novel/Vehicle vs Novel $/$ copolamine, $p>$ 0.9999). c, QR2 mRNA expression reduction following novel cage was seen in mice that received eticlopride or vehicle, but not $\mathrm{SCH}$, compared with control home cage mice (Familiar $1.002 \pm 0.0252^{-\Delta \Delta \mathrm{ct}}, n=7$; Novel/Vehicle $0.863 \pm 0.0172^{-\Delta \Delta \mathrm{ct}}, n=10$; Novel/SCH $0.968 \pm 0.0242^{-\Delta \Delta \mathrm{ct},}, n=10$; Novel/Eticlopride $0.886 \pm 0.0102^{-\Delta \Delta^{\prime} \mathrm{ct}}, n=5$; one-way ANOVA, $F_{(3,28)}=8.751, p=0.0003$; Tukey's multiple comparisons test, Familiar vs Novel/Vehicle, $p=0.0007$; Familiar vs Novel/SCH, $p=0.7041$; Familiar vs Novel/Eticlopride, $p=0.0207$; Novel/Vehicle vs Novel/SCH, $p=0.0047$; Novel/Vehicle vs Novel/Eticlopride, $p=0.9056$; Novel/SCH vs Novel/Eticlopride, $p=0.1088$ ). $\boldsymbol{d}$, miR-182 expression levels were significantly elevated following novel cage exposure, in mice receiving vehicle compared with SCH or familiar cage controls (Familiar $1.112 \pm 0.1312^{-\Delta \Delta \mathrm{Ct}}, n=13$; Novel/Vehicle $2.053 \pm 0.3612^{-\Delta \Delta \mathrm{ct}}, n=5$; Novel/SCH $0.750 \pm 0.2142^{-\Delta \Delta \mathrm{ct}}, n=6$; Kruskal-Wallis test, $p=0.0084$; Dunn's multiple comparisons test, Familiar vs Novel/Vehicle, $p=0.0473$; Familiar vs Novel $/ S \mathrm{CH}, p=0.773$; Novel/Vehicle vs Novel $/ \mathrm{SCH}, p=0.0076$ ). e, DAT-Cre mice injected with Cre-dependent hM4Di in LC that received vehicle, and mice injected with Credependent mCherry that received CNO both showed a decrease in QR2 mRNA following novel cage exposure, but those expressing hM4Di that received CNO did not, compared with those that were kept in their home cages (Familiar $1.004 \pm 0.0392^{-\Delta \Delta \mathrm{ct}}, n=6$; Novel/hM4Di + Vehicle $0.845 \pm 0.0442^{-\Delta \Delta \mathrm{Ct}}, n=6$; Novel/hM4Di + CNO $0.925 \pm 0.032^{-\Delta \Delta \mathrm{ct}}, n=6$; Novel/mCherry + CNO $0.749 \pm 0.028, n=5$; one-way ANOVA, $F_{(3,19)}=8.091, p=0.0011$; Tukey's multiple comparisons test, Familiar vs Novel/Vehicle, $p=0.0294$; Familiar vs Novel/ CNO, $p=0.3553$; Novel/Vehicle vs Novel/CNO, $p=0.3408)$. $\boldsymbol{f}$, Representative image of $\mathrm{LC}$ dopaminergic neurons, expressing hM4Di inhibitory DREADD. Data are mean \pm SEM. ${ }^{*} p<0.05$. ${ }^{* *} p<0.01$. ${ }^{* *} p<0.001$. ${ }^{* * *} p<0.0001$.

\section{QR2 reduced expression following novel context is D1R- and not D2R- or mAChR-dependent}

Changes in QR2 and miR-182 expression following a novel stimulus are dependent on the local neuromodulation necessary for novel memory formation, which differs across the brain (Rodríguez-García and Miranda, 2016; Moreno-Castilla et al., 2017; Gould et al., 2020). In the aIC, ACh is exceptionally dominant (Gal-Ben-Ari and Rosenblum, 2012; Linster and Fontanini, 2014) and long-acting neuromodulator following novelty, whereas in the hippocampus, dopamine is centrally important (Li et al., 2003; Kempadoo et al., 2016). In the aIC, we have shown the QR2 pathway is dependent on cholinergic modulation. In order to test which neuromodulator lies upstream of QR2 suppression in CA1, we first familiarized mice with intraperitoneal injections (containing saline), to prevent a novelty effect from the injection itself. Then, mice were given either the muscarinic ACh receptor (mAChR) antagonist scopolamine $(2 \mathrm{mg} / \mathrm{kg})$, or vehicle. After $40 \mathrm{~min}$, the mice were taken by a different laboratory member to a novel context cage (see Materials and Methods), and kept there for $15 \mathrm{~min}$. They were then returned to their home cages and killed $3 \mathrm{~h}$ later, and QR2 mRNA was compared with mice that received vehicle and returned to their home cages instead of being taken to the novel context (Fig. 3a). In contrast to the aIC, we found that scopolamine had no effect on QR2 expression in CA1, which similarly to the mice that received vehicle, was significantly reduced compared with the mice that remained in a familiar context (Fig. 3b).

Since dopamine release in the hippocampus has been shown to be correlated with novelty, we repeated the experiment with mice that instead of receiving scopolamine, received either D1R antagonist SCH 23390 (henceforth, SCH), or dopamine D2 receptor (D2R) antagonist eticlopride (both $0.05 \mathrm{mg} / \mathrm{kg}$ ). The animals were killed $3 \mathrm{~h}$ following novel context exposure and compared with mice that received vehicle and were either kept in familiar cages or the novel context, as before. We found that, on novel context exposure, $\mathrm{SCH}$ alone prevented QR2 mRNA expression reduction (Fig. 3c).

Since miR-182 upregulation is tied to QR2 mRNA downregulation, we repeated the novel context experiment with $\mathrm{SCH}$ and vehicle and killed the mice $1 \mathrm{~h}$ later to measure miR-182 levels. The obtained results demonstrate upregulation of miR-182 in CA1, which SCH completely prevented (Fig. $3 d$ ). In light of these findings, and since it has been recently shown that the LC is the major dopaminergic input to CA1 following incidental novelty learning (Kempadoo et al., 2016; Takeuchi et al., 2016), we assessed LC involvement in QR2 expression reduction. To do so, DAT-Cre mice (The Jackson Laboratory, stock \#006660) were injected to the LC with a Cre-dependent inhibitory DREADD (hM4Di) expressing viral vector, or a control vector (mCherry). These mice were then given either vehicle or $\mathrm{CNO}(1 \mathrm{mg} / \mathrm{kg}$, i.p.) and returned to their home cages for $40 \mathrm{~min}$. As described above, they were then taken to a novel context while one of the two groups that received vehicle were kept in their familiar home cages. After $3 \mathrm{~h}$, the animals were killed and the brains were removed and dissected such that the hippocampus was flash frozen in liquid nitrogen to measure QR2 expression, while the LC was fixed by immersion in 4\% PFA for imaging (see Materials and Methods; Fig. 3f). We found that mice that were injected to the LC with the Cre-dependent hM4Di virus and received CNO, and therefore had reduced dopaminergic input from the LC to CA1, did not show a significant reduction in QR2 mRNA, while those injected with vehicle did show a significant reduction in 
a
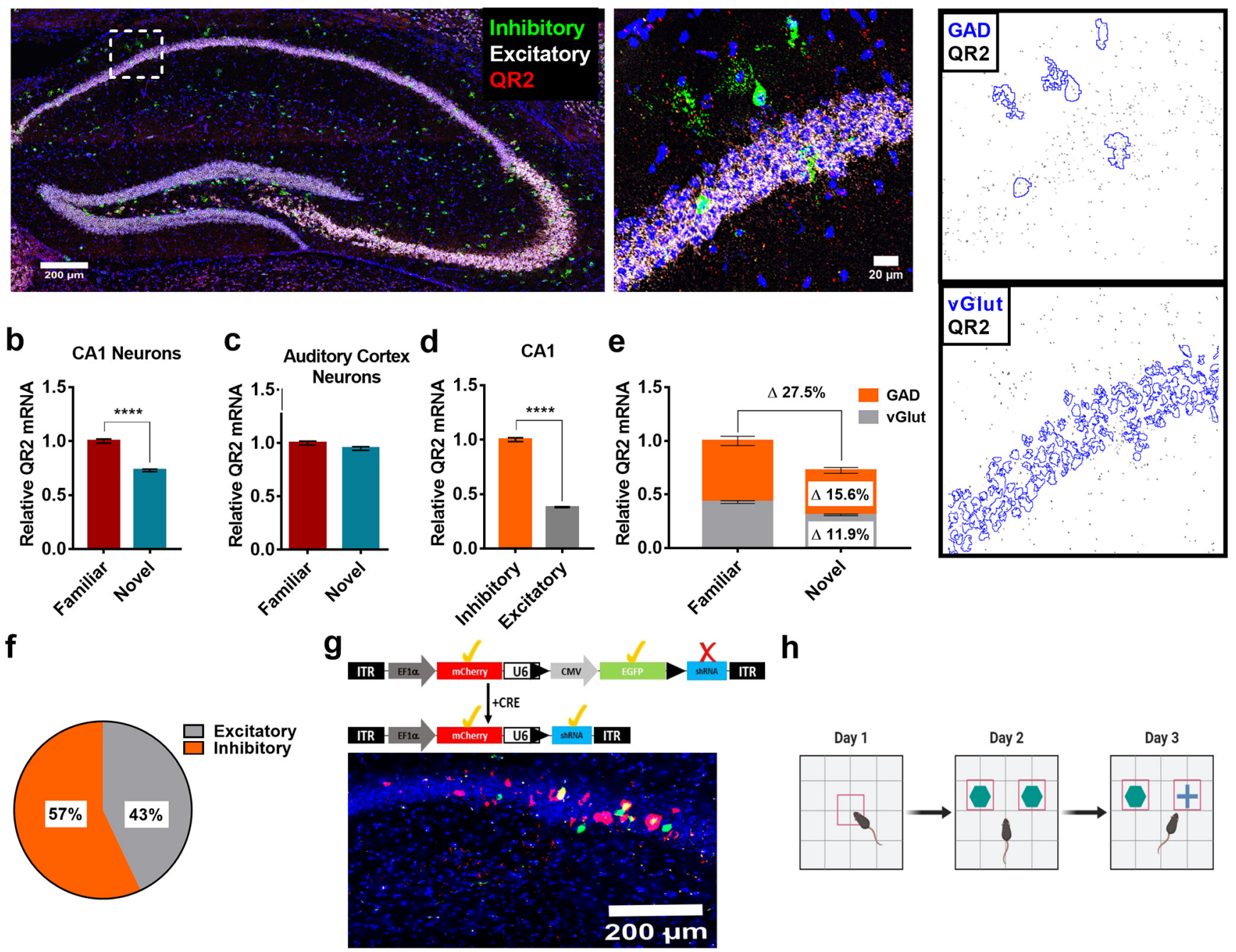

\section{h}
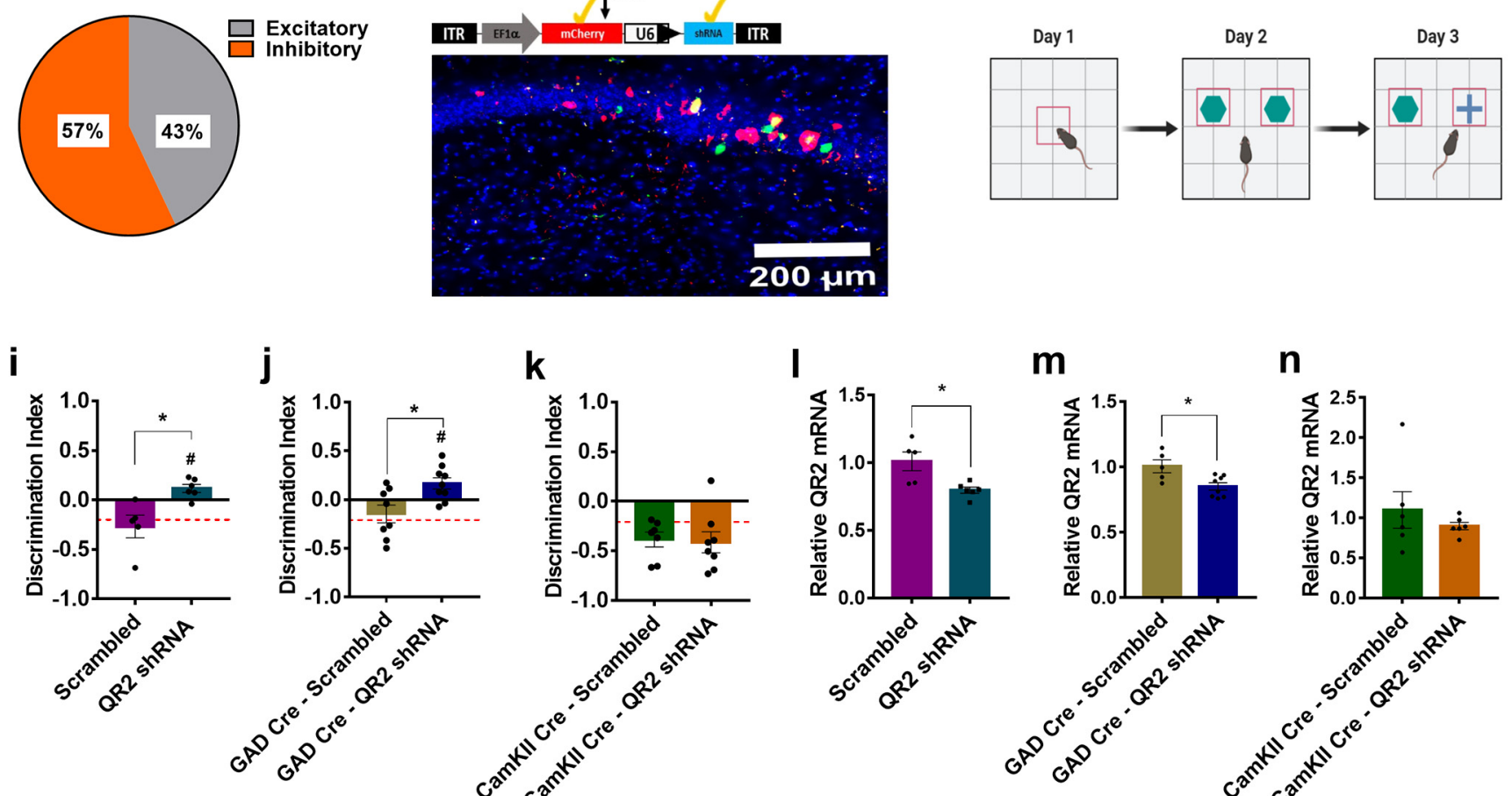

k

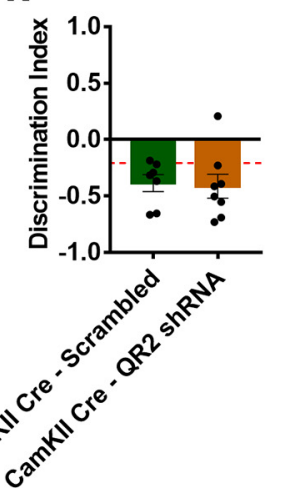

I

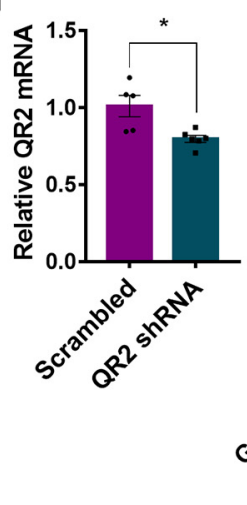

m

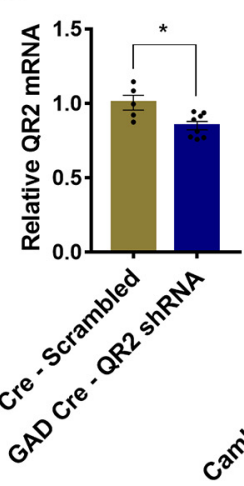

n

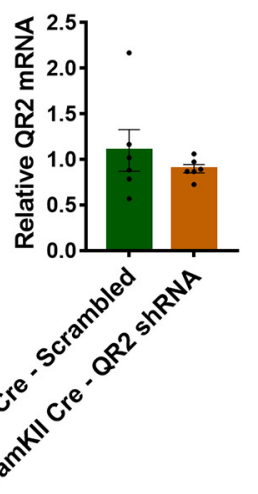

Figure 4. Reduced $Q R 2$ expression in inhibitory interneurons improves novel object memory. $\boldsymbol{a}$, A representative image of the mouse dorsal hippocampus using RNAscope probes to mark excitatory (vGlut) and inhibitory (GAD) neurons, as well as QR2 mRNA. Cell nuclei were stained with DAPI. QR2 was quantified by mean density per cell area, denoted by masks based on GAD, vGlut, and DAPI. $\boldsymbol{b}$, QR2 mRNA was significantly reduced in CA1 of mice that underwent novel context exposure (Familiar $1 \pm 0.019 \mathrm{AU}$, $n=2755$ cells from $n=4$ mice; Novel $0.729 \pm 0.011 \mathrm{AU}, n=5301$ cells from $n=4$ mice; Mann-Whitney test, $p<0.0001$ ). c, QR2 mRNA was unchanged in the auditory cortex control area (Familiar $1 \pm 0.018$ AU, $n=2751$ cells from $n=4$ mice; Novel $0.949 \pm 0.016 \mathrm{AU}, n=2452$ cells from $n=4$ mice; Mann-Whitney test, $p=0.7002$ ). $\boldsymbol{d}$, Inhibitory neurons display significantly higher levels of QR2 compared with excitatory neurons (Inhibitory $1 \pm 0.017 \mathrm{AU}, n=2714$ cells from $n=4$ mice; Excitatory $0.381 \pm 0.005 \mathrm{AU}, n=5342$ cells from $n=4$ mice; Mann-Whitney test, $p<0.0001$ ). $\boldsymbol{e}, 0$ f the total reduction in QR2 mRNA seen following novel context exposure, $15.6 \%$ was from inhibitory and $11.9 \%$ from excitatory neurons. $\boldsymbol{f}$, From the total $\mathrm{QR2}$ signal measured, $57 \%$ was from inhibitory and $43 \%$ was from excitatory neurons. $\boldsymbol{g}$, Cre-dependent QR2 shRNA virus was injected to GAD Cre mice, or coinjected to WT mice along with CamKII promoter expressed Cre, to CA1. $\boldsymbol{h}$, Mice were exposed to an open field box and left to explore for $10 \mathrm{~min}$. The following day, two identical objects were placed within the box, and the mice were allowed to explore for 10 min. The next day, one of the objects was replaced with a novel object, and the mice were given 10 min to explore. A discrimination index was then calculated. $\boldsymbol{i}$, Mice that were injected with a lentivirus generally expressing shRNA targeting QR2 in neurons showed a significant improvement in discrimination compared with uninjected WT (red dashed line) or scrambled control animals (total exploration time of objects, Scrambled $68.12 \pm 26.87 \mathrm{~s}$; QR2 shRNA $40.25 \pm 19.39 \mathrm{~s} ;$ WT $70.17 \pm 25.74 \mathrm{~s} ;$ object discrimination, Scrambled $-0.267 \pm 0.114$ DI, $n=5 ;$ QR2 shRNA 
QR2 expression, as did those injected with CNO but did not express hM4Di in the LC (Fig. 3e). These data indicate that on novel contextual stimulus, LC-dependent activation of D1R in CA1 causes upregulation of miR-182, which in turn destabilizes QR2 mRNA, enabling QR2 reduction and memory stabilization.

\section{Reduced QR2 expression in inhibitory interneurons improves novel object memory}

In order to better define the circuit and cell type specific to QR2 expression and its reduction in CA1 following novel contextual stimuli, we performed RNAscope quantitative ISH assay (Venniro et al., 2017). Mice underwent either familiar or novel contextual exposure and were killed $3 \mathrm{~h}$ later, as previously described (Fig. 3). Flash frozen brains were then sliced and hybridized with GAD (for inhibitory neurons), vGlut (for excitatory neurons), and QR2 probes (Fig. 4a, left and middle). Mean QR2 signal was measured within each cell (Fig. $4 a$, right), and a significant reduction was seen in the CA1 neurons of mice that experienced a novel context, consistent with qPCR results (Fig. 4b). Neurons in the auditory cortex that were used as a control located on the same slice as CA1, to allow for interslice signal variation (see Materials and Methods), did not display any change in QR2 expression (Fig. 4c). Interestingly, inhibitory neurons expressed 2 or 3 times the amount of QR2 compared with excitatory neurons (Fig. $4 d$ ) in CA1. This translates into a relative contribution of $15.6 \%$ of the total $27.5 \%$ reduction in QR2 expression being from within inhibitory neurons, compared with just $11.9 \%$ being from within excitatory neurons following novel context exposure (Fig. 4e). Therefore, of the total QR2 signal reduction measured, $57 \%$ was from inhibitory neurons and $43 \%$ from excitatory neurons (Fig. 4f). Given that inhibitory neurons represent only $10 \%-15 \%$ of the total neuronal population in the hippocampus (Pelkey et al., 2017), these data indicate that

\section{$\leftarrow$}

$0.117 \pm 0.040 \mathrm{Dl}, n=6 ; \mathrm{WT}-0.202 \pm 0.0829 \mathrm{DI}, n=5$; one-way ANOVA, $F_{(2,13)}=6.939$, $p=0.0089$; Tukey's multiple comparisons test, Scrambled vs $Q R 2$ shRNA, $p=0.0116$; Scrambled vs WT, $p=0.844$; QR2 shRNA vs WT, $p=0.0341$ ). $\boldsymbol{j}$, GAD (re mice injected with Cre-dependent shRNA targeting QR2 showed a significant improvement in discrimination compared with uninjected WT (red dashed line) or scrambled control animals (total exploration time of objects, GAD Cre-Scrambled $58.42 \pm 16.52 \mathrm{~s}$; GAD Cre-QR2 shRNA $43.06 \pm 14.21 \mathrm{~s}$; WT $70.17 \pm 25.74 \mathrm{~s}$; object discrimination, GAD Cre-Scrambled $-0.147 \pm 0.090 \mathrm{DI}, n=8$; GAD Cre-QR2 shRNA $0.167 \pm 0.058 \mathrm{DI}, n=9$; WT $-0.202 \pm 0.0829 \mathrm{DI}, n=5$; one-way ANOVA, $F_{(2,19)}=6.856, p=0.0057$; Tukey's multiple comparisons test, GAD Cre-Scrambled vs GAD Cre-QR2 shRNA, $p=0.0165$; GAD Cre-Scrambled vs WT, $p=0.891$; GAD Cre-QR2 shRNA vs WT, $p=0.0141)$. $\boldsymbol{k}$, Mice injected with (re-expressing virus under the CamKII promoter and simultaneously with Cre-dependent shRNA targeting QR2 in CA1 showed no difference in NOR compared with uninjected WT (red dashed line) or scrambled control animals (total exploration time of objects CamKII Cre-Scrambled 23.26 \pm 13.2 s; CamKII Cre-QR2 shRNA $106.5 \pm 22.91 \mathrm{~s} ;$ WT $70.17 \pm 25.74 \mathrm{~s}$; object discrimination, CamKII Cre-Scrambled $-0.386 \pm 0.074 \mathrm{DI}, n=7$; CamKII Cre-QR2 shRNA $-0.414 \pm 0.105 \mathrm{Dl}, n=8$; WT $-0.202 \pm 0.0829 \mathrm{DI}, n=5$; one-way ANOVA, $F_{(2,17)}=1.295, p=0.2995$; Tukey's multiple comparisons test, CamKII Cre-Scrambled vs CamKII Cre-QR2 shRNA, $p=0.9734$; CamKII CreScrambled vs WT, $p=0.4134$; CamKII (re-QR2 shRNA vs WT, $p=0.2988$ ). I, Mice injected with QR2 shRNA showed significantly reduced QR2 mRNA levels in CA1 compared with scrambled controls (Scrambled 1.01 $\pm 0.0692^{-\Delta \Delta \mathrm{Ct}}, n=5$; QR2 shRNA $0.796 \pm 0.022$ $2^{-\Delta \Delta \mathrm{Ct}}, n=6$; Student's $t$ test, $\left.t=3.172, \mathrm{df}=9, p=0.0113\right)$. $\boldsymbol{m}, \mathrm{GAD}$ Cre mice injected with Cre-dependent QR2 shRNA showed significantly lower QR2 mRNA levels in CA1 compared with scrambled controls (Scrambled $1.005 \pm 0.0502^{-\Delta \Delta \mathrm{ct}}, n=5$; QR2 shRNA $0.850 \pm 0.028$ $2^{-\Delta \Delta \mathrm{ct}}, n=8$; Student's $t$ test, $\left.t=2.924, \mathrm{df}=11, p=0.0138\right)$. $n$, Mice injected with a Creexpressing virus under the CamKII promoter and simultaneously with Cre-dependent shRNA targeting QR2 in CA1 showed an insignificant reduction in QR2 expression in CA1 (Scrambled $1.096 \pm 0.2292^{-\Delta \Delta \mathrm{ct}}, n=6$; QR2 shRNA $0.895 \pm 0.0462^{-\Delta \Delta \mathrm{ct}}, n=6$; Student's $t$ test, $t=0.8561, \mathrm{df}=10, p=0.4120$ ). Data are mean \pm SEM. ${ }^{*} p<0.05$ versus WT. ${ }^{*} p<0.05$. ${ }^{* * * *} p<0.0001$. inhibitory neurons in CA1 are the primary neuronal subtype in which QR2 is both expressed and suppressed following novel context.

In order to test the significance of this expression pattern in novel contextual memory stabilization, we aimed to assess the effect QR2 expression reduction has on NOR, a form of CA1-dependent incidental novel contextual memory learning paradigm (Fig. 4h). We opted for a weak NOR protocol, in which WT mice did not show any significant preference for the novel object, to assess whether QR2 suppression would enable sufficient memory retention for the novel object, to allow for its discrimination. First, we injected mice with QR2 shRNA or scrambled control expressing viral vectors to $\mathrm{CA} 1$, and following recovery the mice were trained and tested for NOR. QR2 shRNA injected mice remembered the learned, now familiar, object better than those injected with a scrambled control, which did not show preference for the novel object, as measured by discrimination index (Fig. 4i). Next, we tested whether QR2 expression and its suppression within GABAergic inhibitory neurons in CA1 was sufficient to enhance novel contextual memory. We therefore manipulated the CA1 region of transgenic mice expressing Cre regulated by the GAD promoter (The Jackson Laboratory, stock \#010802) with viral vectors expressing a Cre-dependent QR2 shRNA or a scrambled control (Fig. 4g). Following the same NOR procedure, mice injected with Cre-dependent QR2 shRNA displayed significantly improved novel object discrimination compared with controls, which similarly to WT, did not show any object preference (Fig. 4j), confirming the importance of QR2 expression within inhibitory neurons of CA1. In order to assess whether excitatory neurons also contribute to the QR2-dependent improvement in NOR we observed, mice were coinjected with a viral vector expressing Cre regulated by the CaMKII promoter, and a viral vector containing Cre-dependent QR2 shRNA, to CA1. No difference in NOR was seen in mice expressing QR2 shRNA in excitatory neurons of CA1, compared with WT or scrambled controls (Fig. $4 k$ ). Mice injected with the general, and with the Cre-dependent, QR2 shRNA showed a significant reduction in QR2 expression in CA1 compared with their respective controls (Fig. $4 l-n$ ), but not in control regions (control aIC region; general QR2 shRNA, Scrambled $1.002 \pm 0.0342^{-\Delta \Delta \mathrm{Ct}}, n=5$; QR2 shRNA $1.091 \pm 0.0502^{-\Delta \Delta \mathrm{Ct}}, n=6$; Student's $t$ test, $t=1.388$, $\mathrm{df}=9, p=0.1985$; GAD Cre-dependent QR2 shRNA, Scrambled $1.005 \pm 0.0462^{-\Delta \Delta \mathrm{Ct}}, n=6$; QR2 shRNA $0.905 \pm 0.0432^{-\Delta \Delta \mathrm{Ct}}$, $n=8$; Student's $t$ test, $t=1.554, \mathrm{df}=12, p=0.1461$; CamKII Credependent QR2 shRNA, Scrambled $1.007 \pm 0.0562^{-\Delta \Delta C t}, n=6$; QR2 shRNA $0.996 \pm 0.0822^{-\Delta \Delta \mathrm{Ct}}, n=6$; Mann-Whitney test, $p=0.4848$ ). These results point to inhibitory interneurons as the primary site of QR2 expression and its suppression following novelty, whereupon its effect on the formation of a stable longterm memory takes hold, signifying the importance of interneurons in this process.

\section{Inhibitory, but not excitatory, neurons hyperpolarize and show reduced excitability following intracellular QR2 inhibition}

QR2 function is poorly understood in mammalian cells in general and in neurons specifically. We have demonstrated that QR2 activity can increase ROS levels, and thus mediate redox modulation in the brain (Gould et al., 2020) (Fig. 1), which is known to affect neuronal excitability and intrinsic properties (Naseri Kouzehgarani et al., 2020). In order to assess whether QR2 inactivation might therefore directly cause such an effect, we performed whole-cell patch-clamp recordings of both excitatory 
a

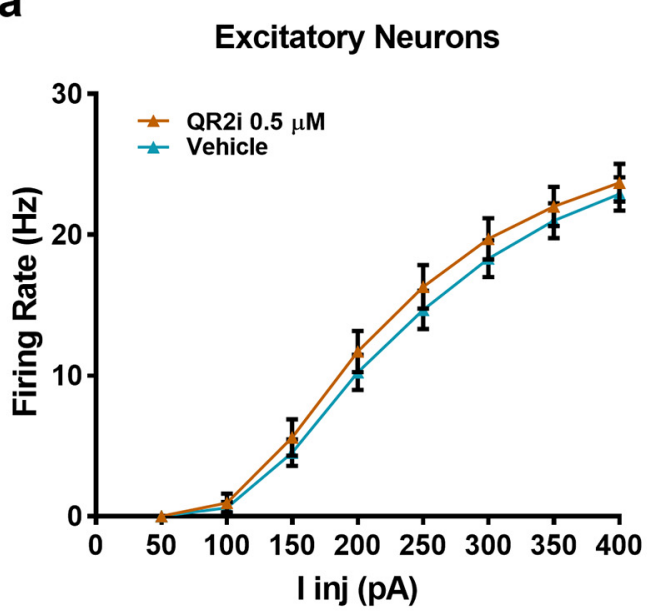

C

\section{Excitatory Neurons}

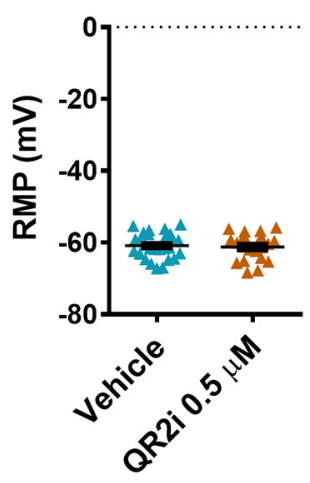

b

\section{Excitatory - Vehicle}

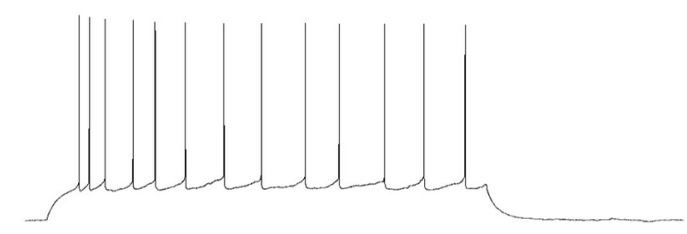

Excitatory - QR2i $0.5 \mu \mathrm{M}$

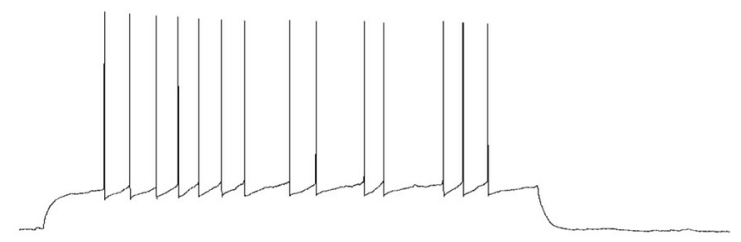

e

Inhibitory Neurons

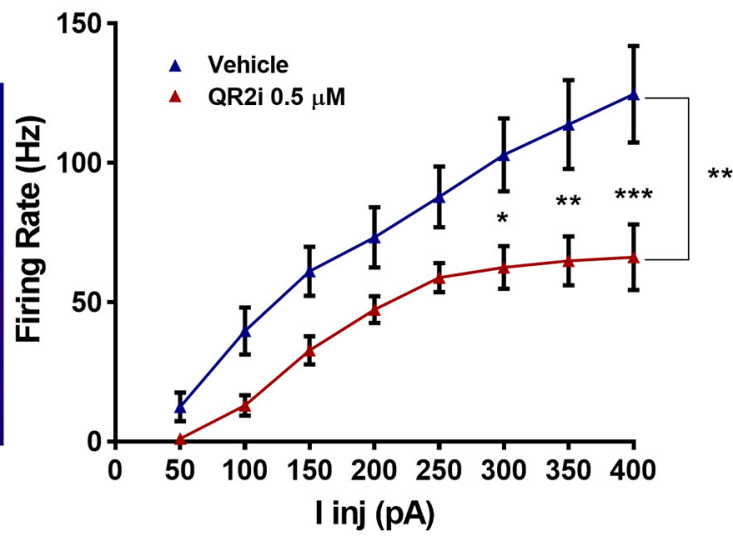

h

i f Inhibitory - Vehicle

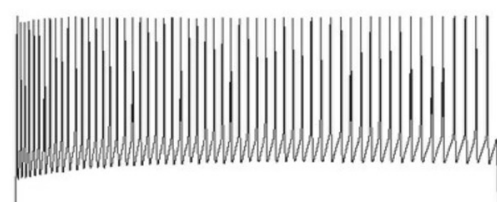

Inhibitory - QR2i 0.5 $\mu \mathrm{M}$

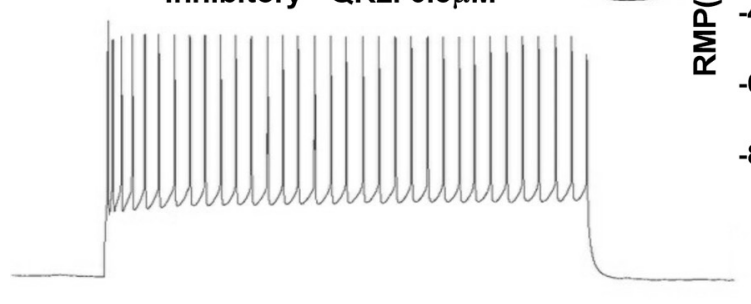

g
Inhibitory Neurons (Red)

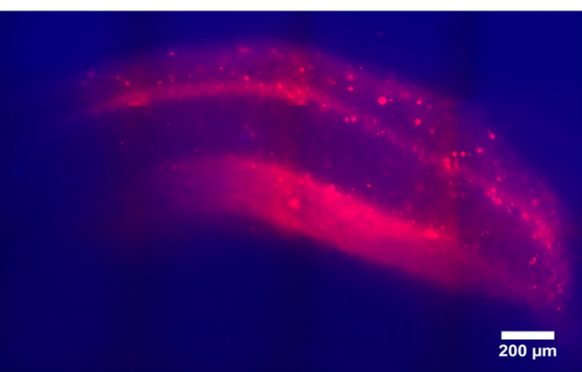

Inhibitory Neurons

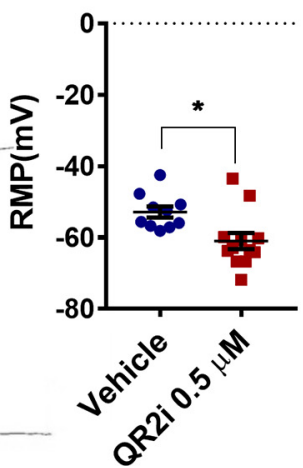

Excitatory Neurons

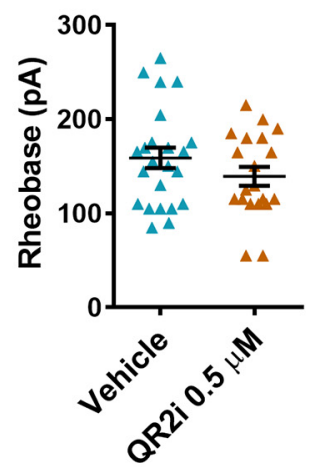

Inhibitory Neurons

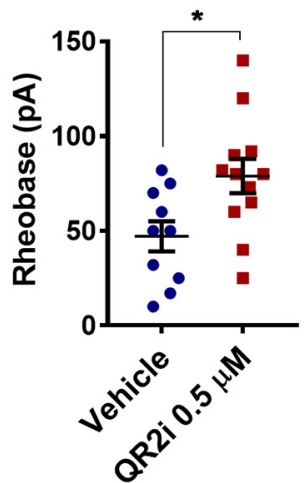

Figure 5. Inhibitory, but not excitatory, neurons hyperpolarize and show reduced excitability following intracellular QR2 inhibition. $\boldsymbol{a}$, Excitatory cells in CA1 show no change in firing rate on intracellular application of QR2 inhibitor S29434 (two-way repeated-measures ANOVA, Pulse $F_{(7,315)}=346.3, p<0.0001$; Treatment $F_{(1,45)}=0.5107, p=0.4785$; Interaction $F_{(7,315)}=0.3242$, $p=0.9428)$. $\boldsymbol{b}$, Representative traces recorded from excitatory neurons in CA1. $\boldsymbol{c}$, Resting membrane potential in unchanged in excitatory neurons of CA1 on the intracellular application of QR2 inhibitor S29434 (Vehicle $-60.86 \pm 0.6677 \mathrm{mV}, n=27$ cells, $n=6$ mice; S29434 $0.5 \mu \mathrm{m}-61.24 \pm 0.8514 \mathrm{mV}, n=20$ cells, $n=4$ mice; Student's $t$ test, $t=0.3569, \mathrm{df}=45, p=0.7228$ ). $\boldsymbol{d}$, GAD-Cre mice were injected to CA1 with Cre-dependent mCherry. Inhibitory neurons are seen in red. $\boldsymbol{e}$, Inhibitory cells in CA1 show a significant reduction in firing rate on intracellular application of QR2 inhibitor S29434 (two-way repeated-measures ANOVA, Pulse $F_{(7,140)}=45.45, p<0.0001$; Treatment $F_{(1,20)}=11.74, p=0.0027$; Interaction $F_{(7,140)}=2.533, p=0.0175$; Sidak's multiple comparisons test of Vehicle vs $5294340.5 \mu \mathrm{m}$ at $50 \mathrm{pA}, p=0.9799 ; 100 \mathrm{pA}, p=0.3018 ; 150 \mathrm{pA}, p=0.2318 ; 200 \mathrm{pA}, p=0.3369 ; 250 \mathrm{pA}, p=0.2105 ; 300 \mathrm{pA}, p=0.0197 ; 350 \mathrm{pA}$, $p=0.0022 ; 400 \mathrm{pA}, p=0.0001)$. $\boldsymbol{f}$, Representative traces recorded from inhibitory neurons in CA1. $\boldsymbol{g}$, Resting membrane potential of inhibitory neurons in CA1 is significantly hyperpolarized on the intracellular application of QR2 inhibitor S29434 (Vehicle $-52.83 \pm 1.56 \mathrm{mV}, n=10$ cells, $n=5$ mice; S29434 $0.5 \mu \mathrm{M}-61.24 \pm 2.275 \mathrm{mV}, n=12$ cells, $n=5$ mice; Student's $t$ test, $t=2.841, \mathrm{df}=20, p=0.0 .0101$ ). $\boldsymbol{h}$, S29434 intracellular application does not alter excitatory cell rheobase (Vehicle $158.8 \pm 10.94 \mathrm{~ms}, n=23$ cells, $n=6$ mice; $\mathbf{S} 294340.5 \mu \mathrm{m}$ 
a

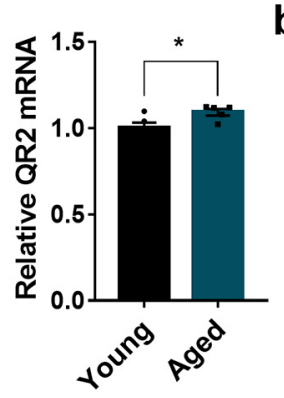

d

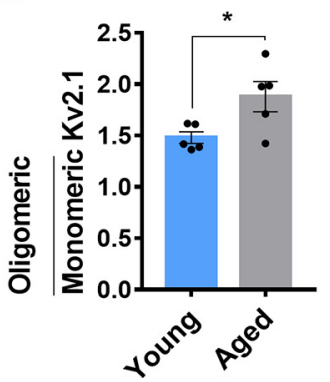

b

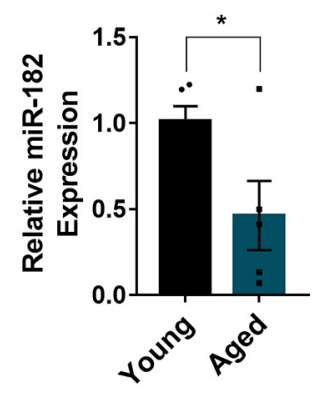

e

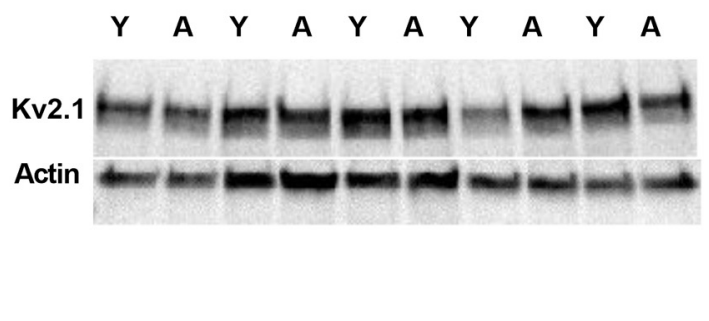

C

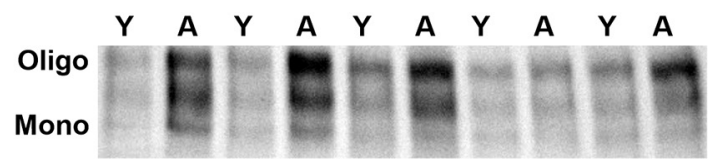

Figure 6. Dysregulation of $Q R 2$ and miR-182 is correlated to increased oxidation in aged mouse hippocampus. $\boldsymbol{a}, \mathrm{QR2}$ mRNA expression is elevated in CA1 of aged compared with young adult mice (3-month-old $1.002 \pm 0.0292^{-\Delta \Delta \mathrm{ct}}, n=5 ; 20$-month-old $1.092 \pm 0.0192^{-\Delta \Delta \mathrm{Ct}}, n=5$; Student's $t$ test, $t=2.55, \mathrm{df}=8, p=0.0341$ ). $\boldsymbol{b}$, miR-182 expression is reduced in CA1 of aged compared with young adult mice (3-month-old $1.014 \pm 0.0842^{-\Delta \Delta c t}, n=5 ; 20$-month-old $0.463 \pm 0.2012^{-\Delta \Delta c t}, n=5$; Student's $t$ test, $t=2.526, \mathrm{df}=8, p=0.0355$ ). $c$, Kv2.1 seminative blot, following nonreducing SDS-PAGE. Top, Oligomeric, oxidized Kv2.1 channels. Bottom, Functional monomers. $Y=3$-month-old, $A=20$-month-old. $\boldsymbol{d}$, Aged, 20-month-old mice show an increase in oxidized and thus oligomerized Kv2.1 channels compared with young, 3-month-old mice (3-month-0ld $1.479 \pm 0.055 \mathrm{AU}, n=5 ; 20$-month-old $1.878 \pm 0.146 \mathrm{AU}, n=5$; Student's $t$ test, $t=2.541, \mathrm{df}=8, p=0.0347)$. e, Total Kv2.1 and actin from the same samples previously shown in their native state, following reduction and boiling. $\mathrm{Y}=3$-month-old, $A=20$-month-old. $\boldsymbol{f}$, No difference is seen in the expression levels of Kv2.1 in 20-month-old mice compared with 3-month-old mice (3-month-0ld $0.5979 \pm 0.061$ AU, $n=5$; 20-month-0ld $0.549 \pm 0.034 \mathrm{AU}, n=5$; Student's $t$ test, $t=0.6882, \mathrm{df}=8, p=0.5108)$. Data are mean \pm SEM. ${ }^{*} p<0.05$.

and inhibitory neurons in CA1, in the presence of either a QR2 inhibitor $(0.5 \mu \mathrm{M}$ of S29434) or a vehicle within the recording pipette. We have previously used similar concentrations of S29434 to measure QR2 enzymatic activity in the mouse brain and found it did not inhibit the closely related NQO1, while completely inhibiting QR2 (Gould et al., 2020). However, on application of the QR2 inhibitor S29434 via the patch pipette, excitatory neurons of CA1 showed no significant change in firing rate (Fig. $5 a, b$ ), resting membrane potential (Fig. $5 c$ ), rheobase (Fig. $5 h$ ), or any other intrinsic property measured (input resistance, Vehicle $110.6 \pm 6.342 \mathrm{~m} \Omega, n=25$ cells, $n=6$ mice; S29434 $0.5 \mu \mathrm{M} 112.1 \pm 7.125 \mathrm{M} \Omega, n=21$ cells, $n=4$ mice; Student's $t$ test, $t=0.1528, \mathrm{df}=44, p=0.8793$; tau, Vehicle $18.62 \pm 1.274 \mathrm{~ms}$, $n=24$ cells, $n=6$ mice; S29434 $0.5 \mu \mathrm{M} 21.55 \pm 1.808 \mathrm{~ms}, n=21$ cells, $n=4$ mice; Student's $t$ test, $t=1.352$, $\mathrm{df}=43, p=0.1835$ ). In order to test whether a similar effect was found in inhibitory neurons, GAD-Cre transgenic mice were injected with a Cre-dependent mCherry reporter enabling positive identification of interneurons (Fig. $5 d$ ), and these were then similarly patched. In contrast to pyramidal cells, a significant reduction in inhibitory interneuron firing rate was found (Fig. $5 e, f$ ), as well as hyperpolarized resting membrane potential (Fig. $5 g$ ) and increased rheobase (Fig. 5i), though not input resistance (Vehicle 228.8 \pm 24.37

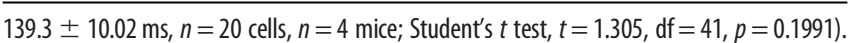
$i$, S29434 intracellular application significantly increases inhibitory cell rheobase (Vehicle $47.1 \pm 7.96 \mathrm{~ms}, n=10$ cells, $n=5$ mice; S29434 $0.5 \mu \mathrm{m} 78.92 \pm 9.017 \mathrm{~ms}, n=12$ cells, $n=5$ mice; Student's $t$ test, $t=2.592, \mathrm{df}=20, p=0.0174)$. Data are mean \pm SEM. ${ }^{*} p<0.05 .{ }^{* *} p<0.01$. ${ }^{* *} p<0.001$. Traces are scaled at $100 \mathrm{~ms}, 20 \mathrm{mV}$ from $350 \mathrm{pA}$ step.
$\mathrm{M} \Omega, n=10$ cells, $n=5$ mice; S29434 $0.5 \mu \mathrm{M} 175.1 \pm 14.53 \mathrm{M} \Omega$, $n=12$ cells, $n=5$ mice; Student's $t$ test, $t=1.943, \mathrm{df}=20$, $p=0.0662$ ) or tau (Vehicle $9.682 \pm 1.436 \mathrm{~ms}, n=10$ cells, $n=5$ mice; S29434 $0.5 \mu \mathrm{M} 9.928 \pm 1.093 \mathrm{~ms}, n=12$ cells, $n=5$ mice; Student's $t$ test, $t=0.02276, \mathrm{df}=20, p=0.9821)$. QR2 therefore alters the intrinsic properties of inhibitory cells, in which it is highly expressed and strongly suppressed. This provides new evidence showing the direct effect of reduced QR2 activity on neuronal excitability, attributing a function to QR2 in the brain for the first time.

Dysregulation of QR2 and miR-182 is correlated to increased oxidation in aged mouse hippocampus

A natural decline in learning and memory occurs with age across mammalian species, as well as an increase in the prevalence of inflammatory pathologies, such as ion channel oxidation, among others, and dementia (Floyd and Hensley, 2002; Cotella et al., 2012; Yin et al., 2016). QR2 causes an increase in ROS, which in the brain can be assessed by Kv2.1 channel oxidation levels, and is associated with certain kinds of dementia (Hashimoto and Nakai, 2011; Janda et al., 2015; Gould et al., 2020). Since miR182 is known to be dysregulated in aged mice (Jawaid et al., 2019) and modulates QR2 during the formation of memory (Gould et al., 2020), we aimed to measure QR2 and miR-182 expression in aged mice ( 20 months old). We found that mRNA expression levels of QR2 are indeed increased in the CA1 of aged mice (Fig. 6a), whereas miR-182 is decreased compared with young mice ( 3 months old; Fig. $6 b$ ). Furthermore, we found that Kv2.1 oxidation is increased in the CA1 of the same aged mice, with a higher ratio of inactive oligomeric channels to functional monomeric channels detected (Fig. $6 c, d$ ). The overall expression 


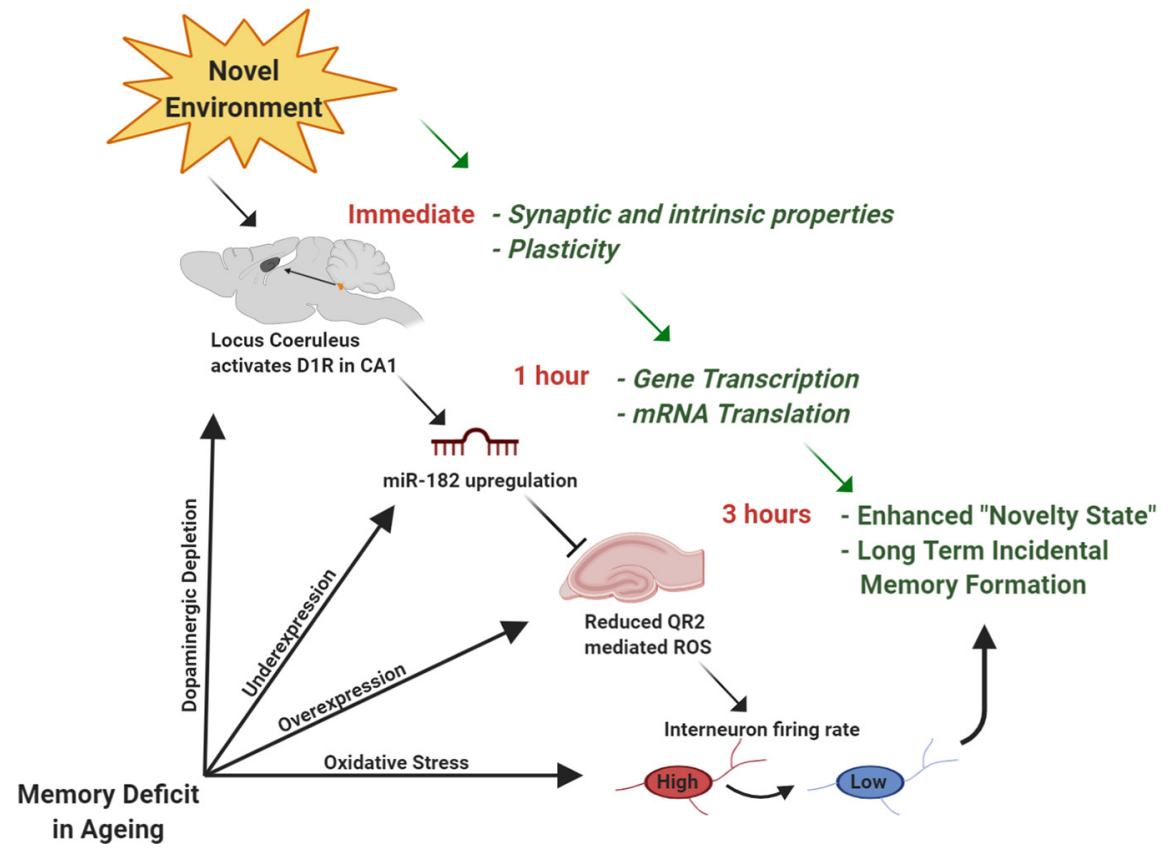

Figure 7. A previously undescribed D1R-dependent pathway in CA1 during novel memory formation, which results in reduced interneuron excitability is mediated by QR2 suppression. Following novel environmental learning, both immediate and long-term molecular and cellular mechanisms have been described (green) that lead to long-term memory formation. Alongside these mechanisms, and entrained by dopaminergic input from the $L C$ to the hippocampus, miR-182 is upregulated and suppresses QR2 expression. QR2 suppression in the brain leads to reduced ROS (Gould et al., 2020), which in CA1 occurs within inhibitory interneurons $3 \mathrm{~h}$ following a novel contextual experience. The reduction in QR2 leads to hyperpolarization and reduced firing of inhibitory interneurons in CA1, which enhances memory facilitation (Makkar et al., 2010).

of Kv2.1, however, was unaltered (Fig. 6e,f). This points to the sensitivity of the QR2 pathway to age, which contributes to memory deficits in aging.

\section{Discussion}

Presently, we showed a hippocampal, dopamine-dependent mechanism of novel memory formation, which acts alongside conventional protein synthesis-dependent molecular consolidation (Fig. 7). This D1R-dependent molecular pathway involves the suppression of QR2 in CA1 via mir182 following novel contextual stimuli, resulting in reduced QR2 activity and its associated ROS production. This reduced physiological ROS (Niki, 2016) in CA1 affects Kv2.1 oxidation levels (Gould et al., 2020) and presumably other redox-sensitive cellular components (Patel and Sesti, 2016; Sesti, 2016; Yu et al., 2019). This alters the intrinsic properties and excitability of CA1 interneurons, linking dopaminergic input and physiological redox modulation of interneurons during memory formation.

Importantly, dopamine release, miR-182 expression, and changes in cellular ROS can all activate many other complex molecular and cellular pathways. However, reduced QR2 expression in inhibitory interneurons is sufficient to produce the potentiating effect of incidental learning and imitates the novelty effect. There is an inherent complexity within the heterogeneous interneuron population found in the hippocampus (Pelkey et al., 2017), which implies a multifaceted effect on reduced firing across these different cells. Therefore, the specific interneuron subtype(s) involved need to be identified to better understand the effect of novelty on interneurons and their output.

The hippocampus is necessary for the formation of novel memories from most sensory modalities and learning exp- eriences in humans and other mammals (Lisman and Grace, 2005). The formation of a novel memory in CA1 requires dopaminergic neurotransmission, which elicits molecular changes, such as NMDA receptor phosphorylation, ERK1/2 activation, and mRNA translation (Fienberg et al., 1998; Li et al., 2003; Kaphzan et al., 2006; Lemon and Manahan-Vaughan, 2012; David et al., 2014, 2020). An additional target of dopamine in CA1 is the upregulation of miR-182, presumably via DARPP32 inhibitory phosphorylation of PP1 (Greengard et al., 1999; Woldemichael et al., 2016). Recently, it was argued that hippocampal novel memory formation is dependent, among other things, on dopaminergic input from the LC (Kempadoo et al., 2016; Takeuchi et al., 2016). Interestingly, the hippocampal "novelty state," similarly to the cortex (Merhav and Rosenblum, 2008), is relatively long and can potentially cause the consolidation of weak, otherwise transient memories, acquired hours following novel stimulus experience (Roth et al., 2005; Moncada and Viola, 2007; Merhav and Rosenblum, 2008; Salvetti et al., 2014). However, it is not clear how novelty causes this effect. Here, we show that the QR2 pathway provides a mechanism, and a conserved convergence point of different neuromodulators and their actions in the paleo and neo cortex, in this phenomenon.

In addition to the role of dopamine in memory formation reported here, it has been previously established that reduced GABAergic neurotransmission in the hippocampus during memory consolidation enhances memory formation, whereas increased GABAergic activity impairs it (Makkar et al., 2010). The exact mechanisms underlying this phenomenon are not entirely understood, despite recent advances. The current work presents a mechanism by which the reported reduction of GABAergic activation can be driven hours following learning to enable persistent memory formation. Specifically, we measured QR2 expression following TFC, a paradigm that requires CA1 for the memory of the context, trace, and tone (Raybuck and Lattal, 2011). We found that QR2 suppression occurred in CA1 following TFC and that either expression reduction or inhibition of QR2 improved hippocampal memory (Fig. 1). Furthermore, novel context exposure alone was sufficient to reduce QR2 expression, following an increase of miR-182 in CA1 (Fig. 2).

Next, we injected mice with miR-182 to CA1, suppressing QR2 locally, and conducted delay fear conditioning, which requires CA1 for memory of the context and the amygdala for memory of the tone (Raybuck and Lattal, 2011). We observed an improvement in contextual memory, but not the tone, demonstrating the ability of miR-182 to suppress QR2, and exemplify the local effect of QR2 suppression on the specific, relevant memory formation. Previous work showed miR-182 expression following novel contextual exposure is necessary for long-term memory formation, and that this is hampered with age (Jawaid et al., 2019). Our results shed further light onto miR-182 memory formation facilitating mechanisms, and allude to dysregulation of QR2 in aging similarly to, and because of, that found in 
miR-182. We also found that D1R activation was necessary for QR2 suppression in CA1 (Fig. 3). We validated these results by inhibiting the major dopaminergic input to CA1, the LC (Kempadoo et al., 2016; Takeuchi et al., 2016), during novel context exposure. No significant change in QR2 expression was detected following novel context exposure in animals that did not receive dopaminergic input from the LC. Although this does not exclude the importance of other inputs (Lisman and Grace, 2005; Smith and Greene, 2012; Moreno-Castilla et al., 2017) for novel contextual memory formation in CA1, it points to the necessity of LC dopaminergic innervation to cause the effect of QR2 there.

Our findings indicate that QR2 is expressed primarily in the inhibitory interneurons of CA1. Intriguingly, previous reports showed that dopamine receptors in the hippocampus are primarily expressed on inhibitory interneurons (Puighermanal et al., 2017), and that miR-182 is expressed in these cells ( $\mathrm{He}$ et al., 2012). Indeed, the primary suppression of QR2 in CA1 occurred in interneurons where its expression levels were initially high (Fig. 4). Importantly, although we found that general suppression of QR2 in CA1 improved NOR, it was only in inhibitory interneurons that this effect was replicated. This points to CA1 interneurons as the primary site within which QR2 suppression enhances novel memory formation. Moreover, it proposes a new mechanism in proteostasis-dependent memory consolidation (Costa-Mattioli et al., 2007; Rosenberg et al., 2014; Santini et al., 2014), and is more localized to interneurons. An open question remains as to why this effect should be localized mainly to these cells, and how it affects them.

Unfortunately, QR2 is a poorly understood enzyme with intriguing features (Vella et al., 2005). For example, many medically approved kinase inhibitors target QR2 (Munoz, 2017), and its natural cofactors are unknown (Boutin et al., 2005). Recently, we demonstrated the ability of QR2 to act as a reductase in the brain, contributing to oxidative eustress there, by continuously releasing a moderate amount of ROS (Gould et al., 2020). We also showed that ROS levels are reduced on QR2 suppression, affecting the redox-sensitive Kv2.1 channel, and presumably other targets sensitive to redox (Patel and Sesti, 2016). However, apart from these findings, no known functional outcome has been described for QR2 in the brain.

Here, we showed that QR2 inhibition within inhibitory, but not excitatory, neurons, reduces excitability (Fig. 5). This unexpected outcome shows how QR2 suppression within CA1 interneurons affects them during memory formation. This places QR2 as an important redox controller of interneurons during their molecular consolidation phase (Santini et al., 2014; Alberini and Kandel, 2015), which contributes to the cellular potentiation observed in CA1 hours following novelty learning. Therefore, it is an example of a brain state-induced by neuromodulation that in turn changes physiological redox within inhibitory cells, transiently affecting the balance of excitation/inhibition. Moreover, the lowered interneuron excitability suggests that, long after novel information is acquired, there is a time window of enhanced excitability (lasting hours), which may allow memory consolidation by changing synaptic strength (Makkar et al., 2010). Another possibility is that QR2 suppression may not act in the formation of the novel memory per se, but instead as a primer to increase allocation for memories subsequent to a novel event to these activated cells, in a manner similar to that of CREB in excitatory neurons (Lisman et al., 2018). However, additional imaging and electrophysiological measurements are needed to better understand the QR2 pathway in the hippocampus.
In aging and disease, a common pathology associated with memory and cognitive deficits is inflammation (Floyd and Hensley, 2002; Yin et al., 2016). QR2 is overexpressed in Alzheimer's disease (Hashimoto and Nakai, 2011) and is controlled by neuromodulation that becomes depleted in neurodegeneration and the aging brain (Mahncke et al., 2006). Furthermore, miR-182 fails to express in the hippocampus of aged mice following NOR, and its overexpression helps improve cognition in aged mice (Jawaid et al., 2019). We found that miR-182 was underexpressed and QR2 was overexpressed, basally, in aged compared with young mice CA1, and that the aged mice also had increased Kv2.1 oxidation levels (Fig. 6). These are hallmarks of aging, inflammation, and cognitive decline, linked by the dysregulated activity of the QR2 pathway. It is possible that in aging, and especially in Alzheimer's disease, the fine balance of maintaining physiological levels of QR2 related ROS is gradually lost, leading to chronic high levels of QR2 expression and activity, culminating in oxidative stress.

Because of the nature and role of the QR2 pathway in learning and memory, it is highly relevant in naturally occurring inflammation and memory loss. It is a newly described component that fits into the dark, unknown space left between depleted neuromodulation, inflammation, and anterograde amnesia associated with aging, which is yet to be adequately described and dealt with. QR2 is a potentially central ingredient to oxidative eustress during memory formation and could be a key to oxidative stress pathologies in aging and dementia. However, important outstanding aspects remain. The development of safe and highly selective inhibitors that are blood-brain barrier permeable would greatly aid in QR2 research and may hold potential as cognitive enhancers for mild cognitive impairment patients.

\section{References}

Alberini CM, Kandel ER (2015) The regulation of transcription in memory consolidation. Cold Spring Harb Perspect Biol 7:a021741.

Boutin JA, Chatelain-Egger F, Vella F, Delagrange P, Ferry G (2005) Quinone reductase 2 substrate specificity and inhibition pharmacology. Chem Biol Interact 151:213-228.

Cassagnes LE, Perio P, Ferry G, Moulharat N, Antoine M, Gayon R, Boutin JA, Nepveu F, Reybier K (2015) In cellulo monitoring of quinone reductase activity and reactive oxygen species production during the redox cycling of 1,2 and 1,4 quinones. Free Radic Biol Med 89:126-134.

Chakraborty D, Fedorova OV, Bagrov AY, Kaphzan H (2017) Selective ligands for $\mathrm{Na}^{+} / \mathrm{K}^{+}$-ATPase $\alpha$ isoforms differentially and cooperatively regulate excitability of pyramidal neurons in distinct brain regions. Neuropharmacology 117:338-351.

Chowdhury N, Quinn JJ, Fanselow MS (2005) Dorsal hippocampus involvement in trace fear conditioning with long, but not short, trace intervals in mice. Behav Neurosci 119:1396-1402.

Costa-Mattioli M, Gobert D, Stern E, Gamache K, Colina R, Cuello C, Sossin W, Kaufman R, Pelletier J, Rosenblum K, Krnjević K, Lacaille JC, Nader K, Sonenberg N (2007) Phosphorylation bidirectionally regulates the switch from short- to long-term synaptic plasticity and memory. Cell 129:195-206.

Cotella D, Hernandez-Enriquez B, Wu X, Li R, Pan Z, Leveille J, Link CD, Oddo S, Sesti F (2012) Toxic role of $\mathrm{K}^{+}$channel oxidation in mammalian brain. J Neurosci 32:4133-4144.

David O, Barrera I, Chinnakkaruppan A, Kaphzan H, Nakazawa T, Yamamoto T, Rosenblum K (2014) Dopamine-induced tyrosine phosphorylation of NR2B (Tyr1472) is essential for ERK1/2 activation and processing of novel taste information. Front Mol Neurosci 7:66.

David O, Barrera I, Gould N, Gal-Ben-Ari S, Rosenblum K (2020) D1 dopamine receptor activation induces neuronal eEF2 pathway-dependent protein synthesis. Front Mol Neurosci 13:67.

Eichenbaum H (2017) Memory: organization and control. Annu Rev Psychol 68:19-45. 
Ferry G, Hecht S, Berger S, Moulharat N, Coge F, Guillaumet G, Leclerc V, Yous S, Delagrange P, Boutin JA (2010) Old and new inhibitors of quinone reductase 2. Chem Biol Interact 186:103-109.

Fienberg AA, Hiroi N, Mermelstein PG, Song W, Snyder GL, Nishi A, Cheramy A, O'Callaghan JP, Miller DB, Cole DG, Corbett R, Haile CN, Cooper DC, Onn SP, Grace AA, Ouimet CC, White FJ, Hyman SE, Surmeier DJ, Girault J, et al. (1998) DARPP-32: regulator of the efficacy of dopaminergic neurotransmission. Science 281:838-842.

Floyd RA, Hensley K (2002) Oxidative stress in brain aging: implications for therapeutics of neurodegenerative diseases. Neurobiol Aging 23:795-807.

Franklin K, Paxinos G (2008) The mouse brain in stereotaxic coordinates. Amsterdam: Elsevier.

Frazzini V, Guarnieri S, Bomba M, Navarra R, Morabito C, Mariggiò MA, Sensi SL (2016) Altered Kv2.1 functioning promotes increased excitability in hippocampal neurons of an Alzheimer's disease mouse model. Cell Death Dis 7:e2100.

Gal-Ben-Ari S, Rosenblum K (2012) Molecular mechanisms underlying memory consolidation of taste information in the cortex. Front Behav Neurosci 5:87.

Gaskin S, Gamliel A, Tardif M, Cole E, Mumby DG (2009) Incidental (unreinforced) and reinforced spatial learning in rats with ventral and dorsal lesions of the hippocampus. Behav Brain Res 202:64-70.

Gould NL, Elkobi A, Edry E, Daume J, Rosenblum K (2020) Muscarinic-dependent miR-182 and QR2 expression regulation in the anterior insula enables novel taste learning. eNeuro 7:ENEURO.0067-20.2020.

Greengard P, Allen PB, Nairn AC (1999) Beyond the dopamine receptor: the DARPP-32/protein phosphatase-1 cascade. Neuron 23:435-447.

Grimm D, Kay MA, Kleinschmidt JA (2003) Helper virus-free, optically controllable, and two-plasmid-based production of adeno-associated virus vectors of serotypes 1 to 6 . Mol Ther 7:839-850.

Gulledge AT, Dasari S, Onoue K, Stephens EK, Hasse JM, Avesar D (2013) A sodium-pump-mediated afterhyperpolarization in pyramidal neurons. J Neurosci 33:13025-13041.

Hashimoto T, Nakai M (2011) Increased hippocampal quinone reductase 2 in Alzheimer's disease. Neurosci Lett 502:10-12.

He M, Liu Y, Wang X, Zhang MQ, Hannon GJ, Huang ZJ (2012) Cell-typebased analysis of microRNA profiles in the mouse brain. Neuron 73:3548 .

Janda E, Lascala A, Carresi C, Parafati M, Aprigliano S, Russo V, Savoia C, Ziviani E, Musolino V, Morani F, Isidoro C, Mollace V (2015) Parkinsonian toxin-induced oxidative stress inhibits basal autophagy in astrocytes via NQO2/quinone oxidoreductase 2: implications for neuroprotection. Autophagy 11:1063-1080.

Jawaid A, Woldemichael BT, Kremer EA, Laferriere F, Gaur N, Afroz T, Polymenidou M, Mansuy IM (2019) Memory decline and its reversal in aging and neurodegeneration involve miR-183/96/182 biogenesis. Mol Neurobiol 56:3451-3462.

Kaphzan H, O’Riordan KJ, Mangan KP, Levenson JM, Rosenblum K (2006) NMDA and dopamine converge on the NMDA-receptor to induce ERK activation and synaptic depression in mature hippocampus. PLoS One 1: e138.

Kempadoo KA, Mosharov EV, Choi SJ, Sulzer D, Kandel ER (2016) Dopamine release from the locus coeruleus to the dorsal hippocampus promotes spatial learning and memory. Proc Natl Acad Sci USA 113:14835-14840.

Kwapis JL, Jarome TJ, Schiff JC, Helmstetter FJ (2011) Memory consolidation in both trace and delay fear conditioning is disrupted by intra-amygdala infusion of the protein synthesis inhibitor anisomycin. Learn Mem 18:728-732.

Lemon N, Manahan-Vaughan D (2012) Dopamine D1/D5 receptors contribute to de novo hippocampal LTD mediated by novel spatial exploration or locus coeruleus activity. Cereb Cortex 22:2131-2138.

Li S, Cullen WK, Anwyl R, Rowan MJ (2003) Dopamine-dependent facilitation of LTP induction in hippocampal CA1 by exposure to spatial novelty. Nat Neurosci 6:526-531.

Linster C, Fontanini A (2014) Functional neuromodulation of chemosensation in vertebrates. Curr Opin Neurobiol 29:82-87.

Lisman J, Cooper K, Sehgal M, Silva AJ (2018) Memory formation depends on both synapse-specific modifications of synaptic strength and cell-specific increases in excitability. Nat Neurosci 21:309-314.

Lisman JE, Grace AA (2005) The hippocampal-VTA loop: controlling the entry of information into long-term memory. Neuron 46:703-713.
Livak KJ, Schmittgen TD (2001) Analysis of relative gene expression data using real-time quantitative PCR and the $2-\Delta \Delta \mathrm{CT}$ method. Methods 25:402-408.

Mahncke HW, Bronstone A, Merzenich MM (2006) Brain plasticity and functional losses in the aged: scientific bases for a novel intervention. Prog Brain Res 157:81-109.

Makkar SR, Zhang SQ, Cranney J (2010) Behavioral and neural analysis of GABA in the acquisition, consolidation, reconsolidation, and extinction of fear memory. Neuropsychopharmacology 35:1625-1652.

Merhav M, Rosenblum K (2008) Facilitation of taste memory acquisition by experiencing previous novel taste is protein-synthesis dependent. Learn Mem 15:501-507.

Moncada D, Viola H (2007) Induction of long-term memory by exposure to novelty requires protein synthesis: evidence for a behavioral tagging. J Neurosci 27:7476-7481.

Moreno-Castilla P, Pérez-Ortega R, Violante-Soria V, Balderas I, BermúdezRattoni F (2017) Hippocampal release of dopamine and norepinephrine encodes novel contextual information. Hippocampus 27:547-557.

Munoz L (2017) Non-kinase targets of protein kinase inhibitors. Nat Rev Drug Discov 16:424-440.

Naseri Kouzehgarani G, Bothwell MY, Gillette MU (2020) Circadian rhythm of redox state regulates membrane excitability in hippocampal CA1 neurons. Eur J Neurosci 51:34-46.

Niki E (2016) Oxidative stress and antioxidants: distress or eustress? Arch Biochem Biophys 595:19-24.

Patel R, Sesti F (2016) Oxidation of ion channels in the aging nervous system. Brain Res 1639:174-185.

Pelkey KA, Chittajallu R, Craig MT, Tricoire L, Wester JC, McBain CJ (2017) Hippocampal GABAergic inhibitory interneurons. Physiol Rev 97:16191747.

Puighermanal E, Cutando L, Boubaker-Vitre J, Honoré E, Longueville S, Hervé D, Valjent E (2017) Anatomical and molecular characterization of dopamine D1 receptor-expressing neurons of the mouse CA1 dorsal hippocampus. Brain Struct Funct 222:1897-1911.

Rappaport AN, Jacob E, Sharma V, Inberg S, Elkobi A, Ounallah-Saad H, Pasmanik-Chor M, Edry E, Rosenblum K (2015) Expression of quinone reductase-2 in the cortex is a muscarinic acetylcholine receptor-dependent memory consolidation constraint. J Neurosci 35:15568-15581.

Raybuck JD, Lattal KM (2011) Double dissociation of amygdala and hippocampal contributions to trace and delay fear conditioning. PLoS One 6: e15982.

Remondes M, Schuman EM (2004) Role for a cortical input to hippocampal area CA1 in the consolidation of a long-term memory. Nature 431:699703.

Rodríguez-García G, Miranda MI (2016) Opposing roles of cholinergic and GABAergic activity in the insular cortex and nucleus basalis magnocellularis during novel recognition and familiar taste memory retrieval. J Neurosci 36:1879-1889.

Rosenberg T, Gal-Ben-Ari S, Dieterich DC, Kreutz MR, Ziv NE, Gundelfinger ED, Rosenblum K (2014) The roles of protein expression in synaptic plasticity and memory consolidation. Front Mol Neurosci 7:86.

Roth DA, Kishon-Rabin L, Hildesheimer M, Karni A (2005) A latent consolidation phase in auditory identification learning: time in the awake state is sufficient. Learn Mem 12:159-164.

Salvetti B, Morris RG, Wang SH (2014) The role of rewarding and novel events in facilitating memory persistence in a separate spatial memory task. Learn Mem 21:61-72.

Santini E, Huynh TN, Klann E (2014) Mechanisms of translation control underlying long-lasting synaptic plasticity and the consolidation of longterm memory. In: Progress in molecular biology and translational science, pp 131-167. Amsterdam: Elsevier.

Sesti $\mathrm{F}$ (2016) Oxidation of $\mathrm{K}^{+}$channels in aging and neurodegeneration. Aging Dis 7:130-135.

Smith CC, Greene RW (2012) CNS dopamine transmission mediated by noradrenergic innervation. J Neurosci 32:6072-6080.

Song C, Ehlers VL, Moyer JR (2015) Trace fear conditioning differentially modulates intrinsic excitability of medial prefrontal cortex-basolateral complex of amygdala projection neurons in infralimbic and prelimbic cortices. J Neurosci 35:13511-13524.

Squire LR, Genzel L, Wixted JT, Morris RG (2015) Memory consolidation. Cold Spring Harb Perspect Biol 7:a021766. 
Takeuchi T, Duszkiewicz AJ, Sonneborn A, Spooner PA, Yamasaki M, Watanabe M, Smith CC, Fernández G, Deisseroth K, Greene RW, Morris RG (2016) Locus coeruleus and dopaminergic consolidation of everyday memory. Nature 537:357-362.

Tiscornia G, Singer O, Verma IM (2006) Production and purification of lentiviral vectors. Nat Protoc 1:241-245.

Vankov A, Hervé-Minvielle A, Sara SJ (1995) Response to novelty and its rapid habituation in locus coeruleus neurons of the freely exploring rat. Eur J Neurosci 7:1180-1187.

Vella F, Ferry G, Delagrange P, Boutin JA (2005) NRH:quinone reductase 2: an enzyme of surprises and mysteries. Biochem Pharmacol $71: 1-12$.

Venniro M, Caprioli D, Zhang M, Whitaker LR, Zhang S, Warren BL, Cifani C, Marchant NJ, Yizhar O, Bossert JM, Chiamulera C, Morales M, Shaham Y (2017) The anterior insular cortex $\rightarrow$ central amygdala glutamatergic pathway is critical to relapse after contingency management. Neuron 96:414-427.e8.

Woldemichael BT, Jawaid A, Kremer EA, Gaur N, Krol J, Marchais A, Mansuy IM (2016) The microRNA cluster miR-183/96/182 contributes to long-term memory in a protein phosphatase 1-dependent manner. Nat Commun 7:12594.

Yin F, Sancheti H, Patil I, Cadenas E (2016) Energy metabolism and inflammation in brain aging and Alzheimer's disease. Free Radic Biol Med 100:108-122.

Yu W, Zhang H, Shin MR, Sesti F (2019) Oxidation of KCNB1 potassium channels in the murine brain during aging is associated with cognitive impairment. Biochem Biophys Res Commun 512:665-669.

Zola-Morgan S, Squire LR, Amaralt DG (1986) Human amnesia and the medial temporal region: enduring memory impairment following a bilateral lesion limited to field CA1 of the hippocampus. J Neurosci 6:2950-2967. 